Accepted for publishing in Engineering Structures

This is rewieved and accepted author's manuscript.

Article is published in Engineering Structures, Volume 204, 1 February 2020, 110019.

DOI: 10.1016/j.engstruct.2019.110019

History: Received 8 March 2019, Revised 28 September 2019, Accepted 27 November 2019, Available online 19 December 2019. 


\title{
A simplified risk-targeted decision model for the verification of the seismic performance of critical infrastructure components to the operational limit state
}

\author{
Francesca Celano ${ }^{1}$, Matjaž Dolšek ${ }^{1}$ \\ ${ }^{1}$ Faculty of Civil and Geodetic Engineering, University of Ljubljana, Jamova 2, SI1000, Ljubljana, Slovenia
}

\begin{abstract}
A simplified risk-targeted decision model for the verification of the seismic performance of infrastructure components to the operational limit state is presented. It assumes linearity between the intensity measure and the engineering demand parameter and includes an evaluation of the displacement demand for a hazard-targeted design earthquake and of the displacement capacity, which is defined as the ratio between the operational limit-state displacement and a risktargeted safety factor. The latter depends on the seismicity of the relevant location, on the randomness of the intensity measures causing the operational limit-state, and on the acceptable (target) probability of exceeding this limit state. In the paper, the theoretical background of risk-targeted safety factor is first explained, followed by a discussion on the sensitivity of the risk-targeted safety factor to the input parameters. The design procedure involving the simplified risktargeted decision model is then introduced and demonstrated by means of an example of a simple pipe rack located at a petrochemical plant. Within the scope of the presented example, the operational limit-state displacement of the pipe rack is estimated on the basis of the limit-state strains of a pipe attached to the frame. The risk-targeted safety factor is then evaluated, and the frame is designed. It is shown that the application of the proposed procedure is straightforward once the operational limit-state displacement has been determined. The advantage of the procedure is that the target risk is accounted for by the risk-targeted safety factor, which can be calculated with respect to the importance of the equipment of the critical infrastructure. Additionally, the proposed decision model can be easily adopted by engineers, because the seismic demand is calculated by analogy to the Eurocode. However, at this stage of the research, the application of the proposed decision model is limited to structures that do not exhibit any significant nonlinear seismic response at the operational limit state, and to structures where the equal displacement rule applies.
\end{abstract}

Keywords: operational limit state, decision model, risk-targeted design, seismic risk, critical infrastructure, pipe racks

\section{Introduction}

Structures in seismic regions have to be designed in such a way that the requirements of no-collapse and damage limitation are met (e.g. [1]). However, in the case of critical infrastructures, several other limit states may be recognized. Guidelines for seismic design and qualification for Nuclear Power plants, as discussed in [2], and several standards for the seismic design of process plants (e.g. [3][4]), take into account the verification of the performance of plants for the Operating Basis Earthquake (OBE) and Safe Shutdown Earthquake (SSE). It is required that the plant remains fully operational immediately after the OBE, which means that the equipment of the plant remains substantially elastic without any damage. In the case of SSE, specific components important for nuclear safety must be designed to remain functional. However, the equipment subjected to SSE may suffer some damage, provided that it remains functional. In addition, another performance objective in the case of petrochemical plants is that the loss of the hazardous material stored in the critical components of the plant has to be prevented, because the release of hazardous material can result in disastrous consequences not only for the plant itself but also for everyone living in its close vicinity [5][6][7]. If the components of the industrial facilities are not designed adequately, the consequences can be severe, such as quite frequently reported after some past earthquakes [8][9]. For these reasons, components of the critical infrastructures should, in general, be verified for several limit states.

In conventional earthquake-resistant design, the limit states are verified by considering the seismic demand corresponding to a design earthquake, which is characterized by a designated occurrence rate (e.g. [1][10][11]). Such an approach is intuitive and familiar to engineers, but the performance of the infrastructure is verified only for the seismic design intensity, whereas the effects of other earthquakes that may occur during the lifetime of the infrastructure are neglected. Being aware of this issue, regulators in 
several European countries tried to increase the level of safety in seismic design by increasing the occurrence rate that characterizes the design earthquakes [12]. However, the issue was overcome by introducing a risktargeted decision model [13]. In the SAC/FEMA approach [13], the seismic demand and capacity are defined by engineering demand parameter (EDP). The seismic demand is risk-dependent, and the decision model considers safety factors in the demand and the capacity side of the decision model. In practice, the application of EDP-based approach is quite challenging, as discussed elsewhere [14]. Alternatively, the seismic demand and the capacity can be expressed by the intensity measure (IM). The IM-based probabilistic formats [15][16][17][18] were developed prior to the EDP-based probabilistic format [13][15], but their application is more practical, although the seismic demand in the case of the IM-based probabilistic format [15] is still risk-dependent.

Later on, many variants of seismic design procedures with the consideration of risk metrics were introduced [19][20][21][22][23][24][25][26][27][28]. These design procedures can be iterative, based on nonlinear response history analysis, or non-iterative using linear elastic analysis. However, the introduction of quantitative risk-based design is a very challenging task, because the procedure is computationally extremely demanding, especially in the case of a complex infrastructural system. For practical applications, simplifications are needed. One possibility, which was implemented in the building codes in the USA [27], involves replacing uniform hazard maps with risk-targeted hazard maps, which were introduced by Luco et al. [29]. Pilot studies addressing risk-targeted hazard maps for mainland France [30] and for Europe [31] were also performed. The seismic design action based on risk-targeted design maps is also risk-dependent. However, an alternative to decision models involving the risk-dependent definition of seismic action has recently been introduced. In this case, the seismic demand is independent of seismic risk, while the risk is controlled by the risk-targeted safety factor, which is the only safety factor applied at the capacity side of the decision model. The risk-targeted safety factor can be used in conjunction with nonlinear analysis [14] or force-based design in order to quantify a risk-targeted reduction factor [28].

In this paper, an attempt has been made to introduce a simplified risk-targeted decision model for the verification of the seismic performance of a structure to the operational limit state. The decision model is applied to the verification of the structure, whereas the capacity of the structure is defined on the basis of the exceedance of the operational limit state in the critical equipment belonging to the structure. However, the simplified risk-targeted decision model is intentionally derived with consideration of Eurocode's decision model, which is familiar to engineering practitioners and which is not based on risk-dependent seismic design action. This means that the seismic demand is related to a certain design earthquake, whereas the displacement capacity is obtained by dividing the operational-limit-state displacement by the risktargeted safety factor, which is derived by taking into account the target (acceptable) probability for the loss of operation of the critical component of the infrastructure. The risk-targeted safety factor is the only safety factor applied on the capacity side, whereas the seismic response analysis of the structure is consistent with Eurocode's approach that is familiar to engineers. It should be emphasized that the proposed decision model is intentionally introduced in a form which is similar to the form of the decision model for the verification of damage limitation in [1], which accounts for the deformation of a structure in order to prevent the exceedance of the damage limitation limit state.

In the paper, the simplified risk-targeted decision model for the verification of the operational limit state is first presented. A risk-targeted safety factor is introduced for the verification of the performance of the structure in order to guarantee the operation of critical equipment with a predefined target (acceptable) probability of exceedance. The theoretical background for the evaluation of this risk-targeted safety factor, which involves the estimation of the spectral acceleration causing the operational limit state for a target probability of exceedance, is also explained. An expression for the definition of such a risk-targeted safety factor in closed form is derived as well. In the second part of the paper, the design procedure, which includes the proposed risk-targeted decision model for the verification of the operational limit state, is explained. An application is demonstrated by means of an example of the design of a frame belonging to a pipe rack of the type typically used in petrochemical plants. Some insights into the modelling of such pipe racks, which is 
used to estimate the operational limit-state displacement, are also presented.

\section{The simplified risk-targeted decision model for the verification of operational limit state}

\subsection{Definition of the simplified risk-targeted decision model}

The introduced risk-targeted decision model for the verification of the seismic performance of a structure to the operational limit state is derived from the decision model for the verification of damage limitation limit state exceedance of Eurocode 8 [1]:

$$
d_{r} v \leq \alpha h
$$

where $d_{r}$ is the interstorey drift, $h$ is the storey height, $v$ is a reduction factor which takes into account a shorter return period of the seismic action associated with the damage limitation requirement (it usually has a value equal to 0.4 or 0.5 ), and $\alpha$ is the proportion of the storey height associated with the displacement causing the damage limitation limit state.

The Eurocode's decision model for the verification of the damage limitation limit state is well understood by engineers. The left hand part of the decision model (Eq.(1)) represents the demand, whereas the right hand part represents the capacity. Interstorey drift $d_{r}$ is the effect of a design earthquake characterized by the basic return period associated to the verification of ultimate limit states (e.g. a return period of 475 years in the case of buildings of ordinary importance). Factor $v$ is approximately calibrated in such a way that the seismic demand $d_{r} v$ on the left hand side of Eq.(1) corresponds to a design earthquake with a lower return period, which is prescribed for the verification of the DL limit state (e.g. 95 years in the case of buildings of ordinary importance). Thus the determined demand should be less than the displacement capacity (i.e. the right hand side of Eq.(1)).

The decision model according to Eq.(1) may be understood as a hazard-targeted decision model, since the demand corresponds approximately to an earthquake with a designated return period. The model can be used to check that the seismic demand is less than the capacity, but only for the seismic intensity level corresponding to the selected return period of the design earthquake. The reliability of exceedance of the limit state is thus not known, but it is controlled by the selection of the return period of the design earthquake. However, specific ground motions can cause exceedance of the limit state even at an intensity lower than the intensity of the design earthquake. Additionally, earthquakes with a higher level of intensity can occur, but their effect is disregarded in the conventional decision model, which is hazard-targeted. These limitations of hazard-targeted decision models may be problematic in the case of critical components of the infrastructure (e.g. petrochemical plants), for which the exceedance of the operational limit state can trigger a loss of functionality and business interruption, which can result in large economic losses or even societal disasters.

For this reason, it could be advantageous to verify the seismic performance of structures using a risk-targeted decision model, which means that the performance objective is defined by the target (i.e. acceptable) risk of exceedance of the operational limit state (e.g. probability of exceedance of limit state for a period of one year) rather than by the target hazard (e.g. by the return period of a design earthquake). Thus, the risktargeted decision model prescribes that the performance of a structural system is acceptable if the probability of exceedance of the designated limit state is lower than the target probability.

Furthermore, in order introduce a model that is familiar to engineer practitioners, it makes sense to introduce the risk-targeted decision model with minimal modifications of the well-known hazard-targeted decision model used in Eurocode 8. This can be achieved by introducing a risk-targeted safety factor into the conventional Eq.(1). Since the objective is the verification of the operational (OP) limit state, the simplified risk-targeted decision model can be defined based on Eq.(1) as follows: 
$d_{D} \leq \frac{d_{O P}}{\gamma_{O P}}=\frac{\alpha_{O P} h}{\gamma_{O P}}$

where $d_{D}$ is the demand displacement, $d_{O P}$ is the best estimate of the displacement causing the operational limit state, i.e. operational-limit-state displacement, which can be expressed by the product $\alpha_{O P} h$, where $\alpha_{O P}$ is the percentage of the storey height associated with the displacement causing the operational limit state, $h$ is the storey height by analogy to Eq.(1), and $\gamma_{O P}$ is the risk-targeted safety factor. It is worth emphasizing that the seismic demand is in general aleatoric, but in the code-based decision model (Eq.(1)) displacement $d_{r}$ is a deterministic variable. Therefore, in the model proposed in this paper, the aleatoric nature of the seismic action, the target risk and the effect of the seismic design intensity used to evaluate the demand displacement $d_{D}$ are all taken into account in $\gamma_{O P}$, the derivation of which is presented in the following section.

The definition of the proposed risk-targeted decision model (Eq.(2)) is similar to that from Eq.(1). It is still based on the concept of comparing the demand and the capacity. The demand still corresponds to a certain return period of the design earthquake, but the capacity is controlled by the physical damage corresponding to the operational limit state and by a risk-targeted safety factor.

The model proposed in this paper is different from the previously introduced risk-based decision models, which use EDP-based or IM-based format [13][15]. In the proposed decision model, the seismic demand is risk-independent. The risk is controlled by a risk-targeted safety factor, which is the only safety factor applied at the capacity side of the decision model. However, assumptions are needed in the calculation of the risk-targeted safety factor, because the response of the structure, which is not yet fully defined in the design phase, cannot be precisely evaluated. The details about this are explained below.

\subsection{Derivation of the risk-targeted safety factor for the verification of the operational limit state}

The risk-targeted safety factor $\gamma_{O P}$ is derived in such a way that the decision model introduced by Eq.(2) implicitly ensures that the annual probability of exceeding the OP limit state is lower than the target (acceptable) annual probability $P_{t, O P}$. For this reason, the theoretical background for the calculation of the risk-targeted fragility function is firstly presented, followed by a derivation of the risk-targeted safety factor $\gamma_{O P \text {. }}$

\subsubsection{Theoretical background for the calculation of a risk-targeted fragility function}

The basis for the calculation of a risk-targeted fragility function for the OP limit state is the conventional risk equation for the estimation of the annual probability of exceeding a limit state due to the effects of earthquakes [32][33][34]. Because the objective of this study is to verify the performance of a structure to the operational limit state, the spectral acceleration at the fundamental period of a structure can be considered as the appropriate seismic intensity measure. In the case that the dynamic coupling between the structure and the equipment is significant, then some other seismic intensity measure may be better for the risk evaluation.

However, since in the design phase the fragility function is not known, the seismic risk equation should be written in the following form:

$$
\lambda_{t, O P}=\int_{0}^{\infty} P\left(\mathrm{OP} \mid S=S_{a}\right)_{t} \cdot\left|\frac{d H\left(S_{a}\right)}{d S_{a}}\right| \cdot d S_{a}
$$


where $S$ is a random variable representing the seismic intensity measure (i.e. the spectral acceleration at the fundamental vibration period), $S_{a}$ is the value of spectral acceleration at the fundamental vibration period, $H\left(S_{a}\right)$ is the hazard function at the site of the structure (Figure 1a) which expresses the annual rate of exceedance of a spectral acceleration $S_{a}, P\left(\mathrm{OP} \mid S=S_{a}\right)$ is the risk-targeted fragility function for the operational limit state (Figure $1 b$ ), which is an unknown function, and $\lambda_{t, O P}$ is the target rate of exceedance of the OP state over a period of one year, which in an input in the case of the risk-targeted design approach.
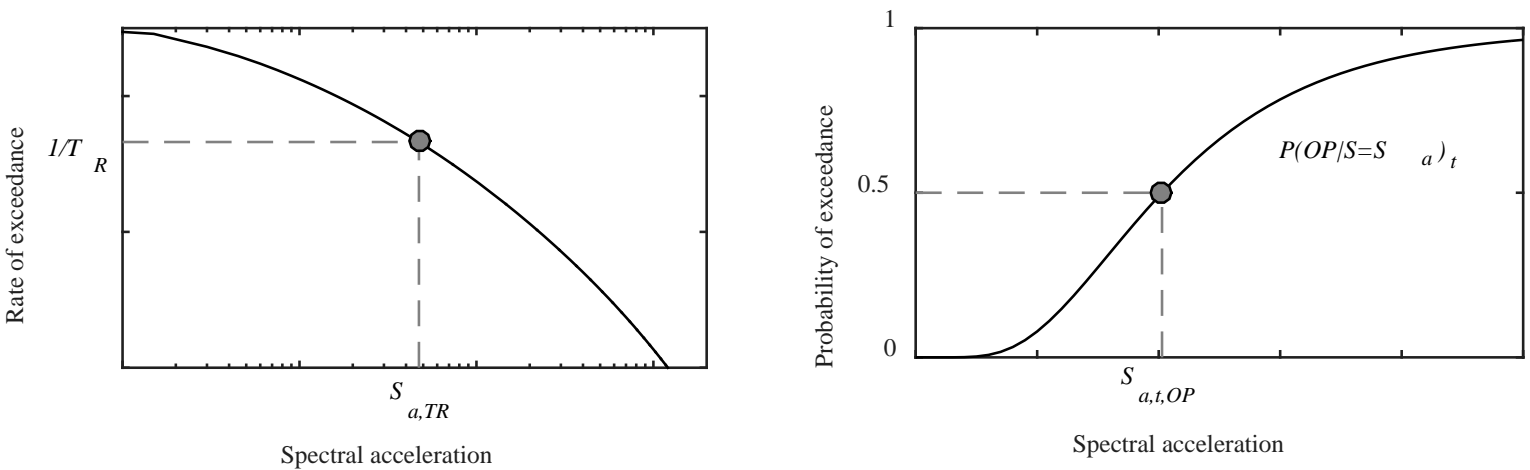

Figure 1. (a) The hazard function and the spectral acceleration $S_{a, T R}$ corresponding to the rate of exceedance equal to the inverse of the return period $T_{R}$, and (b) the risk targeted fragility function showing the median spectral acceleration $S_{a, t, O P}$ causing the OP limit state.

Note that $\lambda_{t, O P}$ is the inverse of the target return period of the exceedance of the OP limit state $\left(\tau_{t, O P}\right)$. Based on the assumption of a Poisson distribution, $\lambda_{t, O P}$ can be calculated from the known target annual probability of exceedance of the operational limit state $P_{t, O P}$ :

$\lambda_{t, O P}=\frac{-\ln \left(1-P_{t, O P}\right)}{1 \text { year }}$

From Eq.(4) it can be easily seen that $\lambda_{t, O P} \approx P_{t, O P}$ when $P_{t, O P}<10^{-2}$. Because $\lambda_{t, O P}$ is actually an input parameter in the risk-targeted design approach, the only unknown in Eq.(3) is the risk-targeted fragility function for the operational limit state $P\left(\mathrm{OP} \mid S=S_{a}\right)_{t}$. This concept was used by Luco at al. [29] for the development of risk-targeted seismic design maps. The term "risk-targeted fragility function" is used because the fragility function $P\left(\mathrm{OP} \mid S=S_{a}\right)_{t}$, when coupled with the seismic hazard function, fulfils the condition from Eq.(3), which means that the resulting probability of exceedance is equal to the target risk $\mathrm{P}_{\mathrm{t}, \mathrm{OP}}$. However, this function cannot be precisely calculated, because the structure is not yet designed. Thus, in order to calculate $P\left(\mathrm{OP} \mid S=S_{a}\right)_{t}$, two assumptions are needed. It is first assumed that $P\left(\mathrm{OP} \mid S=S_{a}\right)_{t}$ is a lognormal distribution function defined by $S_{a, t, O P}$ and $\beta_{O P}$, which represent, respectively, the median $S_{a}$ causing the OP limit state for a given target risk (the risk-targeted spectral acceleration), and the corresponding logarithmic standard deviation. However, only one parameter of the fragility function can be calculated from Eq.(3). For this reason, it is recommended that a value of $\beta_{O P}$ is assumed because it can be derived by means of parametric studies for different types of structures [35][36]. As a consequence, the only unknown parameter in Eq.(3) is the risk-targeted spectral acceleration $S_{a, t, O P}$, which can be calculated by bisection or by any other numerical method in order to satisfy Eq.(3).

Note that $S_{a, t, O P}$ can also be calculated analytically using a simplified procedure. In general, there are several possibilities for the derivation of the analytical solution for Eq.(3). In the simplest case it is assumed that the seismic hazard curve $H\left(S_{a}\right)$ is a linear function in a logarithmic domain $\left(H\left(S_{a}\right)=k_{0} S_{a}^{-k}\right)$, where $k$ is the slope and $k_{o}$ is the intercept of the hazard curve. Since it has already been assumed that the target fragility function is defined by a lognormal distribution function with the standard deviation $\beta_{O P}$, the risk can be expressed [37][38][32] as: 


$$
P_{t, O P}=H\left(S_{a, t, O P}\right) \cdot e^{\frac{k^{2} \cdot \beta_{O P}{ }^{2}}{2}}=k_{0} S_{a, t, O P}{ }^{-k} \cdot e^{\frac{k^{2} \cdot \beta_{O P}{ }^{2}}{2}}
$$

However, it should be noted that other closed-form risk evaluation solutions, which can be found in literature [34][39], can also be used. $S_{a, t, O P}$ can then be evaluated in the following closed form by rearranging Eq.(5) [37]:

$$
S_{a, t, O P}=\left(\frac{k_{0} \cdot e^{\frac{k^{2} \cdot \beta_{O P}{ }^{2}}{2}}}{P_{t, O P}}\right)^{\frac{1}{k}}
$$

The risk-targeted spectral acceleration $S_{a, t, O P}$ causing the operational limit state, which is determined either by numerical methods by satisfying Eq.(3), or according to Eq.(6), is used for the evaluation of the risktargeted safety factor $\gamma_{O P}$, as discussed below.

\subsubsection{Derivation of the risk-targeted safety factor $\gamma_{O P}$}

The starting point for the derivation of $\gamma_{O P}$ is the simplified risk-targeted decision model (Eq.(2)). In a hypothetical case the performance of a structure should be optimal, which means that the inequation (Eq.(2)) transforms into the equation:

$d_{D}=\frac{d_{O P}}{\gamma_{O P}}$

Thus, the risk-targeted safety factor $\gamma_{O P}$ can be defined from Eq.(7) as:

$\gamma_{O P}=\frac{d_{O P}}{d_{D}}$

which means that the risk-targeted safety factor is, by definition, the ratio between the operational limitstate displacement and displacement demand, which, however, is not known, because the structure is not yet defined. In order to evaluate the value of $\gamma_{O P}$ defined according to Eq.(8), the displacement demand and the operational limit-state displacement have to be related to the seismic intensity measure causing $d_{D}$ and $d_{O P}$, respectively. Because structures are not allowed to exhibit any significant nonlinear behaviour until the occurrence of the OP limit state, it can be assumed that its behaviour is practically linear until the occurrence of the OP limit state (indicated by the red curve in Figure 2). As a consequence, the displacements and accelerations are proportional, and the ratio between the displacement demand $d_{D}$ and the operational-limitstate displacement $d_{O P}$ from Eq.(8) can be related to the spectral accelerations as follows:

$$
\frac{d_{O P}}{d_{D}}=\frac{S_{a, O P}}{S_{a, T R}}
$$

where $S_{a, O P}$ is the unknown spectral acceleration causing the displacement associated with the OP limit state, whereas $S_{a, T R}$ is the spectral acceleration causing the demand displacement $d_{D}$, i.e. the spectral acceleration at the return period of the seismic action $\left(T_{R}\right)$.

In the derivation of the risk-targeted factor, it has to be realized that $S_{a, O P}$ should be equal to the risk-targeted spectral acceleration $S_{a, t, O P}$. This is shown schematically in Figure 2 by means of the Incremental Dynamic 
Analysis (IDA) [40] curves of an "optimally designed" structure, which present the relationships between displacements and spectral accelerations.

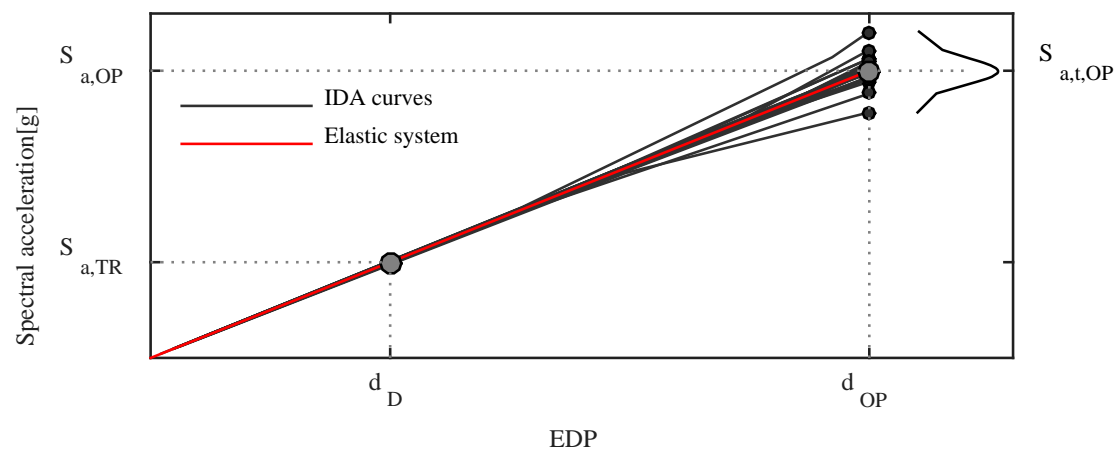

Figure 2. Schematic representation of IDA curves for an "optimally designed"” structure $\left(S_{a, O P}=S_{a, t, O P}\right)$ and the relationship between spectral acceleration and displacement for the linear elastic system

On the basis of the above assumptions, and by taking into account Eq.(8) and Eq.(9), the risk-targeted safety factor can be expressed as:

$\gamma_{O P}=\frac{S_{a, t, O P}}{S_{a, T R}}$

Note that Eq.(10) can also be considered valid if the operational limit state is associated with the nonlinear behaviour of a structure, and if the first vibrational period of the structure is greater than $T_{C}$ (i.e. beyond the intersection between the constant-acceleration and the constant-velocity range of the acceleration response spectrum defined in building codes). In such cases, the "equal displacement rule" applies [41][42], which means that the displacements of the linear elastic structure are "equal" to those of the nonlinear structure. However, in other cases, when the equal displacement rule does not apply, i.e. in the case of structures with short fundamental vibration periods, the definition of the risk-targeted safety factor can be found elsewhere [43].

From the numerator in Eq.(10) it can be concluded that the risk-targeted safety factor depends on the target risk, on seismic hazard function, and on the assumed value of $\beta_{O P}$, whereas the denominator depends on the return period of the design earthquake and on the seismicity at the site of the structure. Two different solutions have been proposed for the evaluation of $\gamma_{O P}$ : the numerical solution and a closed-form solution.

The numerical solution is based on the direct application of Eq.(10). In this case, $S_{a, t, O P}$ in Eq.(10) can be derived by the numerical integration of Eq.(3) by assuming a dispersion $\beta_{O P}$, by considering the hazard function at the site, and by satisfying Eq.(3) in such a way that the rate of exceedance is equal to the target $\lambda_{t, O P}$, as discussed in the previous section. However, $S_{a, T R}$ can also be directly evaluated from the hazard function at the site, for a designated return period of the design seismic action. In the application of Eq.(10), which follows below, it is assumed that the return period of the design seismic action is associated with the ultimate limit state (e.g. return period of 475 years in the case of force-based design). Any other return period of the design seismic action can be used, but it is convenient to use only one return period of seismic action for the verification of all limit states. Such an approach simplifies the process of the seismic analysis, because seismic demand is calculated only for one level of the seismic action, whereas the verification of the limit state is adequately calibrated by the risk-targeted safety factor $\gamma_{O P}$.

Alternatively, the closed-form solution of $\gamma_{O P}$ can be obtained by assuming that the design spectral acceleration $S_{a, T R}$ is evaluated from the approximate hazard function $H\left(S_{a}\right)=k_{0} S_{a}^{-k}$, for the selected return 
period $T_{R}$ :

$S_{a, T R}=\left(k_{0} T_{R}\right)^{1 / k}$

By substituting Eq.(6) and Eq.(11) into Eq. (10), the risk-targeted safety factor can be derived in the following closed-form expression [28][44][45][46]:

$\gamma_{O P}=e^{\frac{k \beta_{O P}^{2}}{2}} \cdot\left(T_{R} \cdot P_{t, O P}\right)^{-1 / k}$

Eq. (12) is a very simple equation providing an insight into the risk-targeted safety factor with respect to the slope of hazard function $(k)$, the target fragility function $\left(\beta_{O P}\right)$, the return period of the design seismic action $\left(T_{R}\right)$, and the target probability of exceedance of the OP limit state affect $\left(P_{t, O P}\right)$ [46].

The proposed EDP-based decision model (Eq. (2)) is derived by considering IM-based risk equation [37][38] (see Eq. (5)). This is possible due to the assumption of the linearity between EDP and IM. As a consequence, $\beta_{O P}$ is IM-based. Alternatively, the same results can be obtained by rearranging SAC/FEMA EDP-format (i.e. Eq. 13 from [13]). In this case, the $\beta$ is EDP-based and, in general, composed of the two dispersions ( $\beta_{D \mid S a}$ and $\beta_{C}$ as defined in [13]). The $\beta_{D \mid S a}$ refers to the EDP-based demand, and it depends on the seismic intensity, while $\beta_{\mathrm{C}}$ refers to the EDP-based capacity.

\subsection{Sensitivity analysis of $\gamma_{O P}$ to the input parameters}

A sensitivity analysis was performed based on the closed-form solution of $\gamma_{O P}$ in order to provide an insight into the importance of the parameters affecting the risk-targeted safety factor $\gamma_{O P}$ (Eq.(12)). The scope of this sensitivity analysis is to investigate the sensitivity of $\gamma_{O P}$ to the variation of target probability $P_{t, O P}$, standard deviation $\beta_{O P}$, and slope $k$ of the hazard function. Note that the return period of the design seismic action was considered equal to $T_{R}=475$ years, which is the usual return period of the design seismic action, as prescribed in Eurocode 8 for ordinary buildings. The risk-targeted safety factor depends on the selected return period $T_{R}$ of the seismic action, as clearly shown by Eq.(12), although the choice of the return period does not affect the final result of the proposed decision model (Eq.(2)). Indeed, demand displacement $d_{D}$ from Eq.(2) and risk-targeted safety factor $\gamma_{O P}$ correspond to the same return period of the seismic design action. Therefore, if a different return period of the seismic design action is considered, both $\gamma_{O P}$ and $d_{D}$ will change, and the decision model will provide the same outcome.

The sensitivity of $\gamma_{O P}$ to variation of the target probability $P_{t, O P} \in\left[5 \cdot 10^{-4}, 5 \cdot 10^{-3}\right]$ is presented in Figure 3 for four values of $\beta_{O P}=[0.1,0.2,0.3,0.4]$. The seven different functions in each diagram represent the effect of the different slopes of hazard function $k$, ranging from $k=1.5$ to $k=3$. The boundary values of the input parameters were selected in such a way that a broad range of possible values used in the design for the operational limit state is taken into account. Note that the red dotted line in Figure 3 highlights a particular value of $P_{t, O P}$ which is equal to the inverse of the considered return period of the design earthquake $\left(T_{R}=475\right.$ years, i.e. $\left.P_{t, O P} \approx \lambda_{t, O P}=1 / T_{R}=0.0021\right)$.

From Figure 3 it can be seen that $\gamma_{O P}$ increases as the target probability $P_{t, O P}$ decreases, and that this trend is more pronounced in the case of lower values of $k$. The value of $\gamma_{O P}$ increases by a factor of up to 5 if $P_{t, O P}$ is decreased 10 times (e.g. from $10^{-3}$ to $10^{-4}$ ). Furthermore, it can be seen that $\gamma_{O P}$ is a linear function of $P_{t, O P}$ within the logarithmic domain (see Figure 4 for $\beta_{O P}=0.1$ ). 


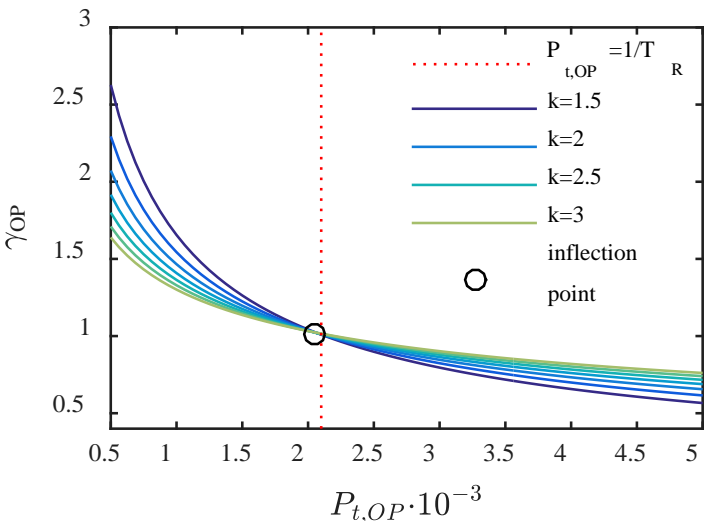

(a)

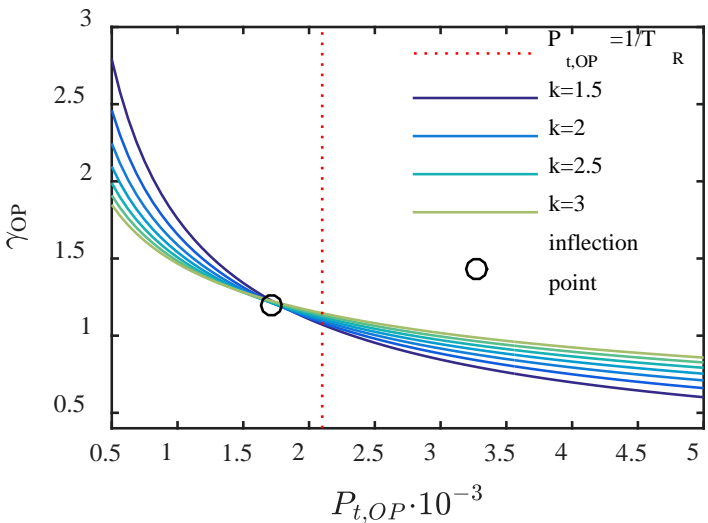

(c)

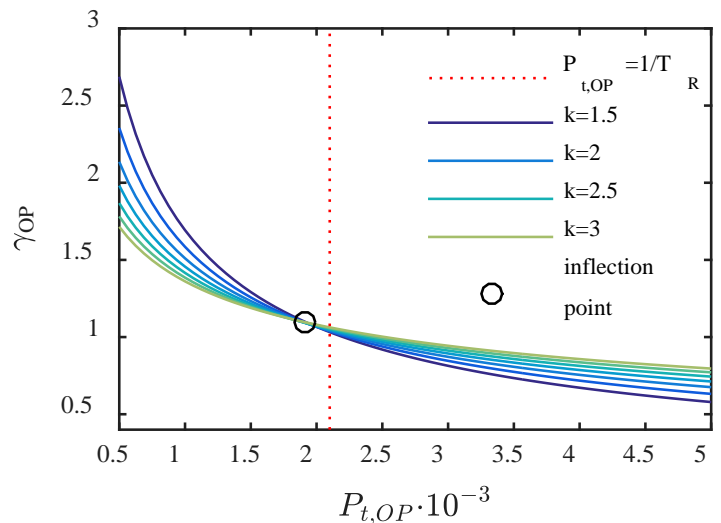

(b)

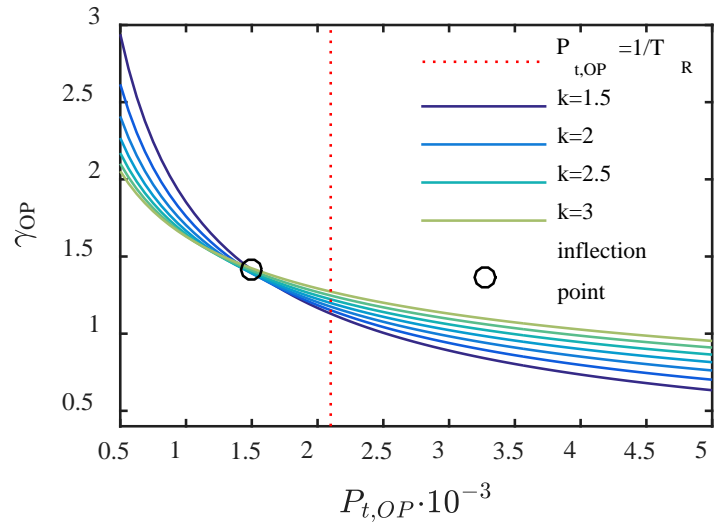

(d)

Figure 3. The sensitivity of $\gamma_{O P}$ to the target probability $P_{t, O P}$ for different values of the slope of hazard function ( $k$ ), and for (a) $\beta_{O P}=0.1$, (b) $\beta_{O P}=0.2$, (c) $\beta_{O P}=0.3$, and (d) $\beta_{O P}=0.4$.

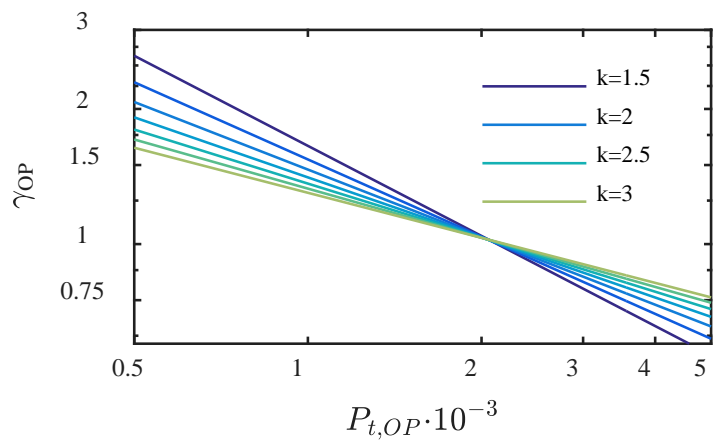

Figure 4. $\gamma_{O P}$ as a function of $P_{t, O P}$ in the logarithmic domain, for different values of the slope of hazard function ( $k$ ) and for $\beta=0.1$

An inflection point of the $\gamma_{O P}$ functions can be observed in each of the diagrams shown in Figure 3 . This fact can be used to define the return period of the design seismic action, such as to minimize the dependence of $\gamma_{O P}$ with respect to the slope of hazard function $(k)$. In the hypothetical case with zero dispersion of the spectral acceleration causing exceedance of the limit state, i.e. $\beta_{O P}=0$, the inflection point occurs for a target probability $P_{t, O P}$ equal to the inverse of the return period of the design earthquake $\left(P_{t, O P}=1 / T_{R}\right)$. With increasing values of $\beta_{O P}$, the inflection point of the $\gamma_{O P}$ functions moves towards lower values of $P_{t, O P}$ (see Figure 3(a), 3(b), 3(c) and 3(d)).

By tuning the return period $T_{R}$ associated with the design earthquake, the inflection point of $\gamma_{O P}$ can be 
moved towards a designated value of $P_{t, O P}$, as is demonstrated in Figure 5 for $\gamma_{O P}$ evaluated for $\beta_{O P}=0.1, k$ ranging from $k=1.5$ to $k=3$ and $T_{R}=325$ years. For comparison, $\gamma_{O P}$ is also presented for the case of $T_{R}=$ 475 years. If, for this particular example, $P_{t, O P}=3 \cdot 10^{-3}$, then $\mathrm{T}_{\mathrm{R}}=325$ years is the return period for the design seismic action, which will minimize the variation of $\gamma_{O P}$ with respect to $k$.

It should be noted that the reduction of the return period from 475 years to 325 years causes an increase of the risk-targeted safety factor. In this case, the displacement demand $d_{D}$ from Eq.(2) decreases due to the use of a lower value of the return period of seismic design action. As a consequence, the outcome of the decision model does not change. However, in Figure 5 it is demonstrated that if $T_{R}$ is equal to the inverse of the target probability of exceedance of the limit state, the slope of hazard function does not significantly affect the risk-targeted safety factor. Nevertheless, in the example presented below, $T_{R}$ was assumed equal to 475 years in order to be consistent with the Eurocode 8 requirements for buildings of ordinary importance.

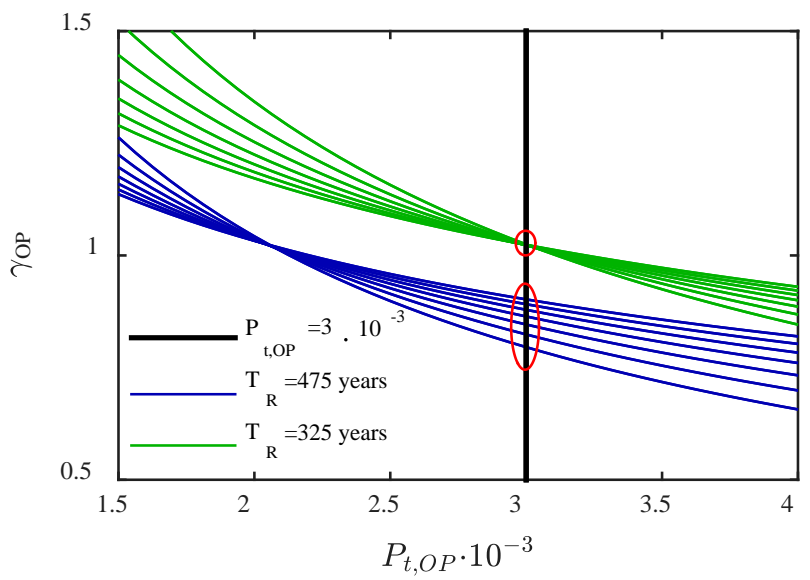

Figure 5. $\gamma_{O P}$ as a function of $P_{t, O P}$ for different values of the slope of hazard function ( $k$ ), for the return periods $T_{R}=475$ years and $T_{R}=325$ years, and for $\beta_{O P}=0.1$. The variation of $\gamma_{O P}$ with respect to $k$ is highlighted for $P_{t, O P}$ $=3 \cdot 10^{-3}$

In Figure $6 \gamma_{O P}$ is presented as a function of $k \in[1.5,3]$ for $\beta_{O P}=0.1$ and for three values of $P_{t, O P}=\left[5 \cdot 10^{-4}, 2.1 \cdot 10^{-3}, 5 \cdot 10^{-3}\right]$, which correspond to target probabilities which apply, respectively, to smaller, equal and greater values than the probability of occurrence of the design earthquake (i.e. the inverse of the selected return period $T_{R}=475$ years). It can be observed that for $P_{t, O P}=5 \cdot 10^{-3} \gamma_{O P}$ increases slightly when the slope of hazard function $(k)$ increases, for $P_{t, O P}=1 / T_{R}, \gamma_{O P}$ is constant and for $P_{t, O P}=5 \cdot 10^{-4} \gamma_{O P}$ decreases when $k$ increases. It can thus be concluded that the trend of $\gamma_{O P}$ with respect to the slope of the hazard function can change the sign which depends on the product $P_{t, O P} T_{R}$. If $P_{t, O P} T_{R}<1$ (i.e. $S_{a, t, O P}>S_{a, T R}$ ), the reduction of $k$ causes an increase in $\gamma_{O P}$, whereas the opposite trend can be observed if $P_{t, O P} T_{R}>1$ (i.e. $\left.S_{a, t, O P}<S_{a, T R}\right)$.
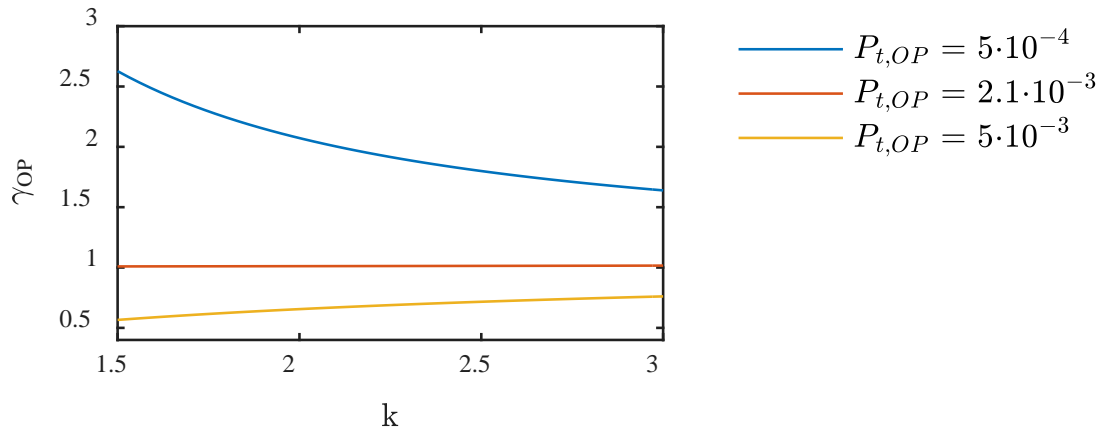

Figure 6. Sensitivity of $\gamma_{O P}$ to the slope of hazard function ( $k$ ) for different values of target probability $P_{t, O P}$ and for $\beta_{O P}=0.1$ 


\subsection{Evaluation of $\gamma_{O P}$ by a numerical solution for selected cases}

In the previous section, $\gamma_{O P}$ was investigated by using the closed-form solution (Eq.(12)). In this section, $\gamma_{O P}$ will be analysed for the hazard functions directly obtained from the probabilistic seismic hazard analysis, using the numerical solution, i.e. by direct application of Eq.(10). $S_{a, T R}$, which in the presented example corresponds to a return period of 475 years, is obtained directly from the seismic hazard function. $S_{a, t, O P}$ is evaluated from the numerical solution of Eq.(3), by fixing a target probability, by assuming a dispersion $\beta_{O P}$, and by considering the hazard function at the site of the structure. In this way, the error due to the approximation of the hazard function in the closed-form solution is eliminated.

Three different locations were taken into account: Bologna, Ljubljana, and Skopje. They are all characterized by the same reference peak ground acceleration (PGA=0.25 g) according to European Seismic Hazard Map 2013 [47]. In general, the risk-targeted safety factor depends on the type of intensity measure (e.g. $S_{a}$ at a vibration period of $T_{1}=0.1 \mathrm{~s}, S_{a}$ at a vibration period of $T_{1}=2 \mathrm{~s}$ ). This impact was also investigated by taking into account a hazard function corresponding to the spectral acceleration for 20 different fundamental periods of structures, ranging from $\mathrm{T}=0.1 \mathrm{~s}$ to $\mathrm{T}=2 \mathrm{~s}$. The hazard functions for spectral acceleration at $\mathrm{T}=0.1 \mathrm{~s}, \mathrm{~T}=1.0 \mathrm{~s}$ and $\mathrm{T}=2.0 \mathrm{~s}$ are presented in Figure 7 for all three investigated sites.

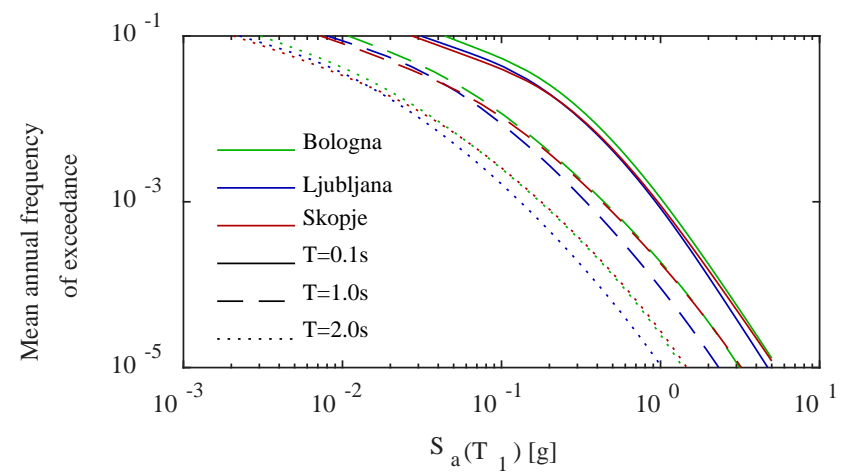

Figure 7. Hazard functions for Bologna, Ljubljana and Skopje. For each location, the hazard functions are presented for three intensity measures (spectral acceleration at $T=0.1 \mathrm{~s}, T=1.0 \mathrm{~s}$ and $T=2.0 \mathrm{~s}$ ).

For simplicity, only one value of the standard deviation of the spectral acceleration causing an operational limit state was taken into account $\left(\beta_{O P}=0.10\right)$. Such a low value is justified by the observation that structures are usually almost elastic at the operational limitation state, so that a low dispersion of the spectral acceleration causing operational limit state can be expected. $\gamma_{O P}$ was then calculated for target probabilities between $P_{t, O P}=5 \cdot 10^{-4}$ and $P_{t, O P}=5 \cdot 10^{-3}$. The results for Bologna, Ljubljana and Skopje are presented in Figure 8. The twenty functions shown in each figure were obtained by taking into account the 20 seismic hazard functions corresponding to the different fundamental periods. 


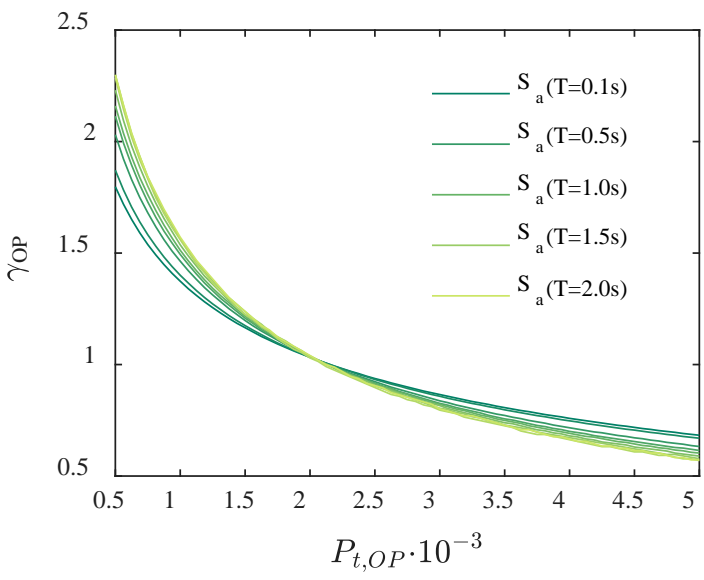

a)

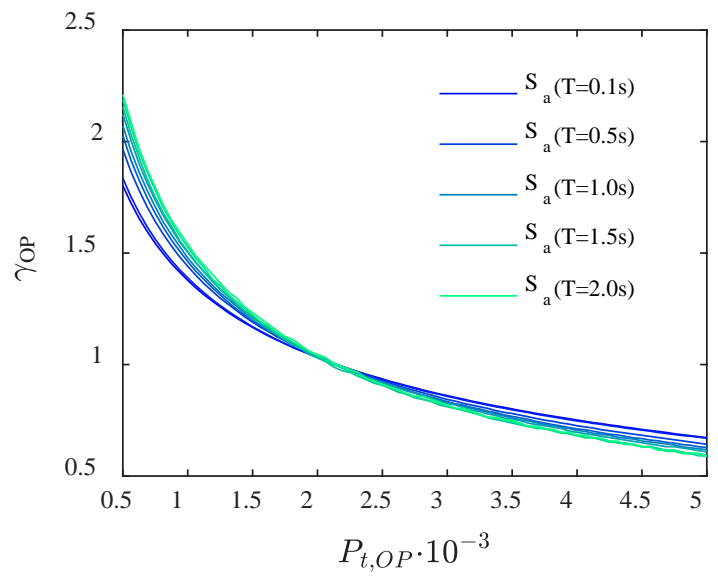

b)

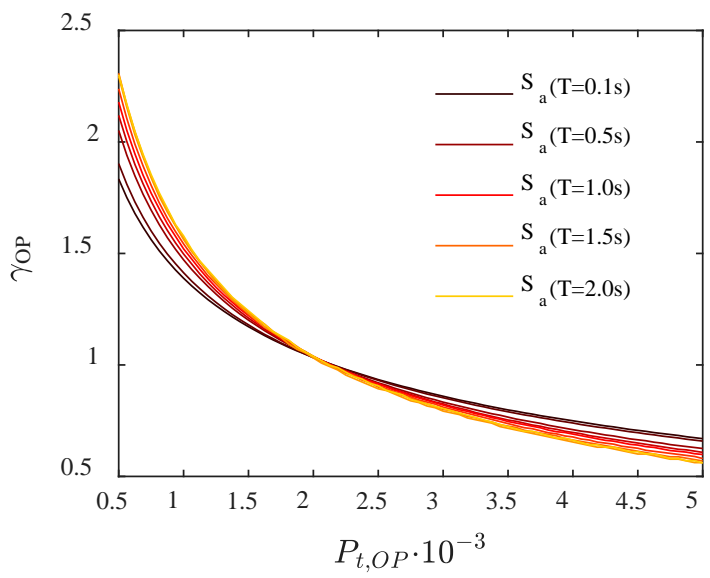

c)

Figure 8. $\gamma_{O P}$ as a function of the target probability of exceedance of the operational limit state for (a) Bologna, (b) Ljubljana and (c) Skopje.

The results indicate that $\gamma_{O P}$ is only slightly affected by different locations. For each of the selected target probabilities and spectral acceleration at a given period, the variation in $\gamma_{O P}$ between the different locations is never greater than $10 \%$. From Figure 8 the variation of $\gamma_{O P}$ due to the impact of different intensity measures $\left(S_{a}(T)\right)$ can also be observed. The lower dispersion of $\gamma_{O P}$ can be observed at $P_{t, O P}=1 / T_{R}=0.0021$, where the functions of $\gamma_{O P}$ tend to intersect. For lower values of the target probability, the impact of the seismic intensity measures $\left(S_{a}(T)\right)$ on $\gamma_{O P}$ increases. $\gamma_{O P}$ can vary by up to $30 \%$ if the spectral acceleration corresponds to a period $T=2.0 \mathrm{~s}$ rather than that of $T=0.1 \mathrm{~s}$. It should be pointed out that $\gamma_{O P}$ is also structure-specific.

\section{Design procedure for the risk-targeted verification of the operational limit state}

The proposed risk-targeted decision model for the verification of the operational limit state (Eq.(2)) can be applied to the design of infrastructures, such as petrochemical plants, for which the maintenance of functionality is a primary objective.

The design procedure that includes the proposed risk-targeted decision model consists of the following steps: (1) definition of the relevant data; (2) assessment of the operational-limit-state capacity; (3) evaluation of the displacement demand; (4) calculation of the risk-targeted safety factor; (5) verification of the 
performance and structural adjustments if the operational limit state is not verified. In general, structural adjustments and some iterations may be needed in order to optimize the design. Each step of the proposed design procedure is described below.

Step 1: Definition of the relevant data. The necessary information about the structure to be designed, such as the materials (reinforce concrete, steel, etc.), about its geometry (e.g. the number of bays and storeys, the span lengths, and the storey heights), and about the applied loads and masses, has to be defined. The location of the structure has to be known, together with the soil type. Furthermore, for the evaluation of the displacement capacity associated with the operational limit state, it is important to acquire data about the different equipment which, if damaged, could affect the functionality of the whole plant. For example, a simple interruption of a cooling system can bring the reactor to a stop, or slight damage to a pipe can cause a massive leakage and stopping of a process. The positions, geometry, and material properties of these components need to be defined. It is also important to have information about how the components are connected to each other and fixed to the structural systems.

Step 2: Assessment of the operational limit-state displacement. The aim of this step is to calculate the displacement $d_{O P}=\alpha_{O P} h$ (Eq.(2)). $\alpha_{O P}$ has the same meaning as coefficient $\alpha$ (Eq.(1)), which has already been proposed in Eurocode 8, and represents the proportion of the storey height of the structure, corresponding to the damage of non-structural elements. It is suggested that $d_{O P}$ is evaluated by means of three sub-steps:

Step 2.1: Identification of the equipment that can cause functionality interruption. The critical equipment, the failure of which causes termination of the operability of the plant, needs to be identified. It could be one important pipe carrying essential fluid for the processes of the plant, or a particular vessel or machine without which the operation of the plant has to be terminated. The outcome of this sub-step depends on the type of plant and on its layout. The result is a list of the critical equipment which can also be used in step 4.

Step 2.2: Definition of the operational limit state of the critical equipment. Once the critical equipment has been identified, the performance criterion corresponding to the operational limit state has to be defined. For example, it could be damage of a pipe, or fracture of an anchor bolt system of a vessel, or many other occurrences depending on the type of equipment. The performance criterion can be related to a damage level, which is usually quantified in terms of the limit stress and/or strain for the equipment.

Step 2.3: Assessment of the limit-state Engineering Demand Parameter (EDP) causing the occurrence of operational limit state of the critical equipment. The limit value of the engineering demand parameter causing a certain damage level is evaluated in this step for each critical equipment. A reliable numerical model of the critical equipment may need to be developed for the computation of the limiting value of EDP, which is usually defined by stresses or strains. It is assumed that the equipment can be modelled independently of the structure, but it is important to consider adequate boundary conditions in order to simulate the interaction with the structure. The deformation of the equipment as a result of (nonlinear) static or dynamic analyses of the equipment itself is then used to estimate the operational limit-state displacement capacity $d_{O P}=\alpha_{O P} h$, as explained below for a specific example.

Step 3: Evaluation of the displacement demand. Drift demand $d_{r}$ of the structure is evaluated by seismic analysis, which is performed on the basis of the design seismic action associated with return period $T_{R}$. For this purpose, a proper model of the structure has to be developed and analysed. Since the objective is to verify the operational limit state, it is often appropriate to estimate the seismic demand by means of linear elastic analysis, due to strict criteria for the operational limit state of the equipment. However, this depends on the value of $d_{O P}$ obtained in step 2.3. 
Step 4: Calculation of the risk-targeted safety factor. The risk-targeted safety factor $\gamma_{O P}$ can be directly estimated from Eq. (10) (the numerical solution) or alternatively by using the closed-form expression (Eq. (12)). First, the acceptable (target) probability $P_{t, O P}$ has to be defined. Depending on the importance of the critical equipment, several different values of $P_{t, O P}$ can be defined as identified in step 2.1. A value of standard deviation $\beta_{O P}$ has to be assumed. This assumption is not critical, because the dispersion of the spectral acceleration causing the exceedance of the operational limit state is expected to be low. Additionally, a very good proxy for $\beta_{O P}$ can be obtained by means of parametric studies [35][48]. It is also suggested that the values of standard deviation $\beta_{O P}$ should be eventually defined in the code, which is in fact proposed in the informative Annex F of the final draft of Eurocode 8 [36]. Values of $\gamma_{O P}$ are calculated for each critical equipment by taking into account a unique seismic hazard function, the defined $P_{t, O P}$ and assumed $\beta_{O P}$. The largest value is used in the proposed risk-targeted decision model. If the seismic hazard analysis is not performed for the site of the infrastructure, at least slope $k$ of the linear seismic hazard function in the logarithmic domain has to be defined in order to calculate the risk-targeted safety factor $\gamma_{O P}$ according to Eq.(12).

Step 5: Verification of the performance and structural adjustments. Demand $d_{r}$ obtained from Step 3 is compared to the displacement capacity (Step 2) divided by $\gamma_{O P}$ (Step 4), according to the decision model of Eq.(2). If the demand is greater than the capacity, the performance of the system is not verified for the operational limit state. This means that the structure or the critical equipment of the system needs to be adjusted. For example, in order to reduce the demand drift, the stiffness of the structure needs to be increased (e.g. by increasing the dimensions of sections of the structural elements or by changing the structural system), or the restraint of the critical equipment can be modified. Steps 3 to 5 have to be re-evaluated iteratively until the demand is at least equal to the capacity. Finally, the final configuration is obtained.

It should be noted that the introduced step-by-step procedure takes into account only one limit state. However, the same procedure can be used to verify the performance of the structure for the safe shutdown condition, for which the allowable damage of the critical equipment can be greater than that assigned to the operational limit state. If it were realized that the nonlinear behaviour of the structure may be allowed, then the risk-targeted safety can be calculated according to Eq.(10) only if the equal displacement rule applies [41][42]. In the opposite case, a definition of the risk-targeted safety factor can still be found elsewhere [43]. If nonlinearity is involved, the value of the standard deviation $\beta$ is recalibrated. Furthermore, it has to be considered that the possible consequences in the case of exceedance of the safe shutdown limit state could be catastrophic, as outlined above. Therefore, in this case, the selected target probability should be significantly lower than that defined for the verification of the operational limit state.

It should be noted that the critical equipment, the failure of which causes termination of the operability of the plant, can be acceleration-sensitive and not only deformation-sensitive, as addressed in Step 2. In this case, the floor acceleration controls the limit state and it would be more appropriate to verify the exceedance of the operational limit state by using IM-based decision model, as introduced elsewhere [43]. However, for the sake of brevity, in the example presented below only the case of deformation-sensitive equipment is considered.

It may also be noted that the dynamic interaction between the structure and the equipment cannot always be neglected. For instance, in the case of primary structure supporting pipes, ASME B31.3 [4] prescribes that the interaction cannot be neglected if the ratio between the weights of pipes and the weight of the supporting structure is more than $25 \%$. In such a case, an assumption that the equipment can be modelled independently of the structure may be too simplistic. This issue can be solved by developing a coupled model of structure and equipment in order to evaluate $d_{O P}$. Alternatively, safety verification can be applied directly to the equipment important for the operation of the plant. For simplicity, this option is not addressed in this paper.

\section{Application of the proposed risk-targeted design procedure to a typical pipe rack}

The design procedure which includes the simplified risk-targeted decision model for the verification of the 
operational limit state is demonstrated by means of an example of a simple pipe rack for a petrochemical plant. In petrochemical plants, as well as in other industrial facilities, pipe racks are used in order to support pipes, power cables, and instrument cable trays and, occasionally, mechanical equipment, vessels, and valve access platforms. They are typically long, narrow structures, characterized by transverse moment-resisting frames, meant to allow maintenance access underneath them [49]. In the state-of-practice the design of pipes and pipe racks is carried out separately, which is also the case in the procedure proposed in Section 3. Pipes are considered part of the mechanical equipment and are usually designed by a mechanical engineer using the allowable stress concept [50]. However, pipe racks are instead treated as frame structures, which are designed by structural engineers using structural codes. The interaction with pipes may be accounted for only by considering the pipe loads and masses. It is important to take into account the deformation of structures in order to prevent failure of the equipment, which can be done by the application of the proposed design procedure.

In the example a part of a typical petrochemical plant is considered. It consists of a massive RC tank, a piping system, and a steel pipe rack (Figure 9). A similar example can be found in [51], but in this case the pipe rack is considered to be made of steel instead of reinforced concrete.

The example is presented following the five steps of the procedure proposed in Section 3. First, the information about the structure as well as about its equipment is given (Step 1), and then the operationallimit-state displacement is assessed (Step 2). For this purpose, a model of the critical equipment is developed and described. This is followed by an evaluation of the seismic demand by means of linear elastic analysis of the structure. The risk targeted safety factor (Step 4) is then evaluated, and finally the performance of the structure is verified (Step 5).

Step 1: The objective is to design the frames of the pipe rack in Figure 9. The structural configuration is the most typical one, as discussed by [49][50][52], and consists of transverse moment-resisting frames connected together by means of longitudinal beams. The geometry of the transversal MRFs is the same as that of the external MRF of the pipe rack in [5] and [53], i.e. it consists of 3 storeys and one bay. The height of the ground-level storey is $5.0 \mathrm{~m}$, whereas the height of other two storeys is $2.0 \mathrm{~m}$. The span length is equal to $6.0 \mathrm{~m}$. Steel of quality S275 was taken into account for the selected HEB and IPE profiles, for the columns and beams, respectively. The considered location is Ljubljana, soil type C, characterized by PGA $=0.25 \mathrm{~g}$.

The piping layout for just one pipe is presented in Figure 9, whereas the presence of other pipes is taken into account in terms of masses used in the design. The layout consists of a straight pipe (pipe B), which is supported by the beams of the transverse frames, and a perpendicular pipe (pipe A), which is connected to a tank. This layout is very typical of petrochemical plants, where pipes carry fluids from and to tanks, and reach other parts of the plant, being supported by pipe racks. 


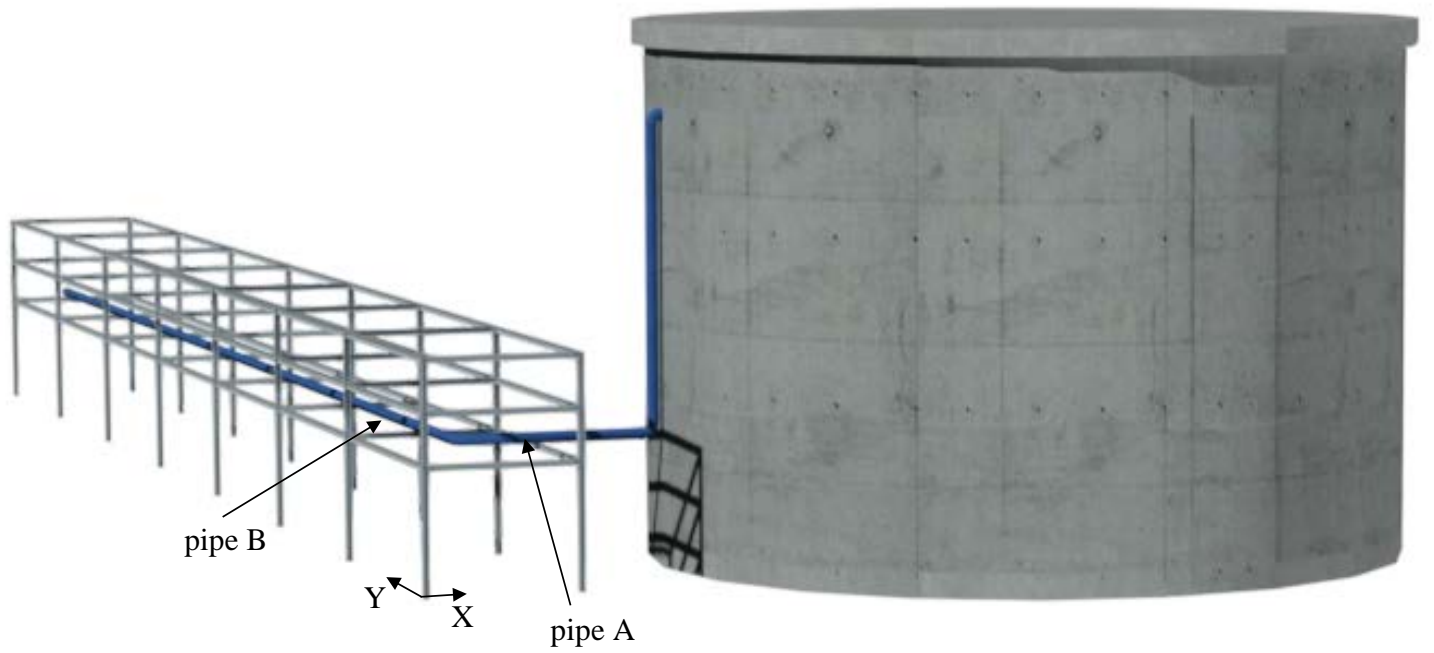

Figure 9. Layout of the pipe-rack and piping system under consideration

The connections between the pipe and the pipe rack are the same as those considered by [5]. Thus, it is assumed that the mechanical supports connecting the pipes to the pipe rack in the $\mathrm{X}$ direction are rigid, whereas in the Y direction the pipe can freely slide on the rack when it moves in the rack's longitudinal direction. For this reason, the excited mass of the pipes is not transferred to the rack for seismic actions in the $\mathrm{Y}$ direction. Consequently, the seismic design for the operational limit state of the entire pipe rack can be restricted to the design of the MRFs in the X direction.

The considered pipe is a 6 inch SCH80 [4], characterized by an external radius of $168.3 \mathrm{~mm}$ and a wall thickness of $11.0 \mathrm{~mm}$. The material is stainless steel grade ASTM A312/TP304L, characterized by a yield strength of $277.3 \mathrm{MPa}$, as defined by experimental tests performed during the course of the INDUSE-2SAFETY project [54]. The pressure inside the pipe is neglected.

Step 2: The operational limit-state displacement is evaluated in the three sub-steps presented in the previous section.

Step 2.1: The functionality of a pipe-rack in a petrochemical plant is related to the performance of the pipes, which are the critical equipment. Indeed, if the pipes are damaged and need to be repaired, the ordinary operations of the plant are interrupted, thus causing a shutdown in functionality. In the case of this specific example, it is assumed that all the pipes are characterized by the same radius, thickness and material, so that only one pipe needs to be identified as critical equipment (Figure 9).

Step 2.2: In this example, the operational limit state of the structure was selected on the basis of damage levels of the pipes, which were classified in [50] and are presented in Table 1. The damage levels "No damage" (DL0), "Minor damage" (DLI), "Major damage without loss of containment" (DLII), and "Major damage with loss of containment" (DLIII) were defined in terms of the intervals of tensile and compressive strains. For this particular example, the operational limit state was defined by the minor damage (DLI), which means that major damages of the pipes are prevented. It is thus assumed that the operational limit state is exceeded when the tensile or the compressive strains exceed the upper limiting values of the interval of strains defined for DLI (i.e. when $\varepsilon_{T}>\varepsilon_{P}$ or $\varepsilon_{C}>\varepsilon_{C u}$ ). It should be noted that in some cases, even the conditions of minor damage without loss of containment (DLI) could require the interruption of operation of a plant. However, the choice of a different damage level does not affect the application of the proposed decision model. 
Table 1. The performance levels for the pipes defined on the basis of limiting values of tensile or compressive strains (Vathi et al. 2017)

\begin{tabular}{|c|l|l|c|}
\hline $\begin{array}{c}\text { Failure } \\
\text { mode }\end{array}$ & Local strain & \multicolumn{1}{|c|}{$\begin{array}{c}\text { Damage level } \\
\text { and corresponding range }\end{array}$} \\
\hline \multirow{2}{*}{$\begin{array}{c}\text { Tensile } \\
\text { fracture }\end{array}$} & Tensile strain $\varepsilon_{T}$ & $\varepsilon_{T} \leq \varepsilon_{y}$ & 0 \\
\cline { 3 - 4 } & & $\varepsilon_{y}<\varepsilon_{T} \leq \varepsilon_{P}$ & $\mathrm{I}$ \\
\cline { 3 - 4 } & $\varepsilon_{P}<\varepsilon_{T} \leq \varepsilon_{T u}$ & $\mathrm{II}$ \\
\cline { 3 - 4 } & & $\varepsilon_{T}>\varepsilon_{T u}$ & $\mathrm{III}$ \\
\hline \multirow{2}{*}{$\begin{array}{c}\text { Local } \\
\text { buckling }\end{array}$} & Compressive strain $\varepsilon_{C}$ & $\varepsilon_{C} \leq \varepsilon_{y}$ & $\mathrm{I}$ \\
\cline { 3 - 4 } & & $\varepsilon_{y}<\varepsilon_{C} \leq \varepsilon_{C u}$ & $\mathrm{II}$ \\
\cline { 3 - 4 } & & $\varepsilon_{C u}<\varepsilon_{C} \leq 5 \varepsilon_{C u}$ & $\mathrm{III}$ \\
\cline { 3 - 4 } & & $\varepsilon_{C}>5 \varepsilon_{C u}$ & \\
\end{tabular}

The damage levels are identified on the basis of tensile and compressive strains. The tensile limit strain $\varepsilon_{T u}$ is assumed to be $2 \%$, as suggested by [50]. Strains $\varepsilon_{y}$ and $\varepsilon_{p}$ correspond to the yielding and the plastic strain of the pipe steel, respectively. The compressive strain resistance $\varepsilon_{C u}$ is expressed by the following relationship [55][6]:

$$
\varepsilon_{C u}=0.5 \frac{t}{D}-0.0025+3000\left(\frac{\sigma_{h}}{E_{s}}\right)^{2}
$$

where $t$ is the thickness of the pipe wall, $D$ is the pipe's external diameter, $\sigma_{h}$ is the internal pressure, and $E_{s}$ is the corresponding Young modulus.

In order to evaluate the type of structural engineering demand parameter which causes damage to the pipe, the layout in Figure 9 has to be analysed. When the moment resisting frame (coloured red in Figure 10) moves in its in-plane direction (i.e. in the $\mathrm{X}$ direction), the mechanical support at node 2 allows pipe A to slide on the rack. Because of the support at node 3, which prevents relative displacements in the transverse direction, pipe B is instead forced to move together with the pipe-rack, as is shown schematically in Figure 10. Thus, the behaviour of the rack causes the opening and closing of the elbow between pipes A and B, causing an increase in the stresses and strains. This was considered to be the worst condition for the entire pipe rack, so that the red-coloured frame in Figure 10 was designed taking into account such a critical condition, and then the same structural configuration was assumed for all the other frames.
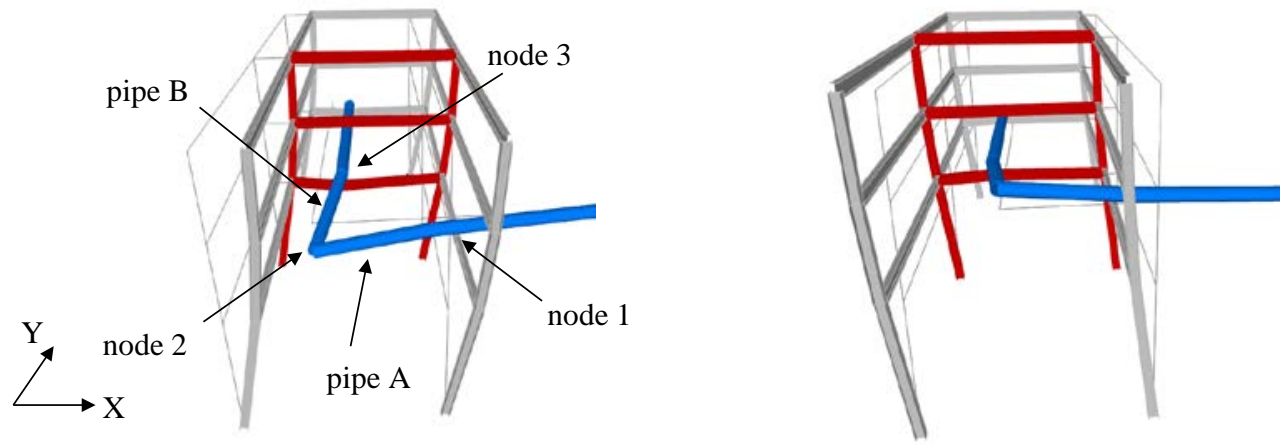

Figure 10. Schematic representation of the opening and closing of the elbow caused by lateral displacement of the 
red $M R F$

Step 2.3: The relationship between the limiting strain in the pipe and the limiting value of the displacement of the pipe rack was investigated on the basis of a model of pipes developed in Opensees (Figure 11a). In the model, node 1 (Figure 10) was considered fully restrained by the RC tank, which is very stiff compared to pipes and pipe racks. The elements "force beam column" with fibre sections were used to model straight pipes, taking into account hollow sections and the uniaxial material "steel02" [56]. Pipes A and B are connected by an elbow, which is the most critical element because of the geometrical irregularity that leads to an intensification of stresses. The European standard [3] suggests that this phenomenon could be taken into account by adjusting the flexibility through a factor $(K)$, which depends on the geometry of the pipe section, obtained as:

$$
K=\frac{1.65}{h}
$$

where $h$ is the flexibility characteristic $h=4 R t / D_{m}^{2}, R$ is radius of the elbow, $t$ is the pipe thickness, and $D_{m}$ is its mean diameter.

Furthermore, to take into account the stress concentration effect, the stresses calculated on the elbow have to be increased using the Stress Intensification Factor (SIF), which is estimated according to the European standards [3], as follows:

$$
S I F=\frac{0.9}{h^{2 / 3}}
$$

$$
\text { (1515) }
$$

where $h$ is the flexibility characteristic $h=4 R t / D_{m}^{2}$, as in Eq.(14).

The model of the elbow was developed according to the procedure used by [6]. Each elbow was characterized by a radius $R$ equal to 1.5 times the diameter of the connected pipes, and it was assumed that the reduction of flexibility spreads across a distance $L$ equal to twice the mean diameter. The two straight parts and the curved part of the elbow were replaced by a straight element (Figure 11b) characterized by a reduced inertia $J^{*}$, obtained as follows [6]:

$$
J^{*}=\frac{\sqrt{2} J(L+R)}{2 L+R K}
$$

where $\mathrm{J}$ is the inertia of the hollow cross-section of the pipe.

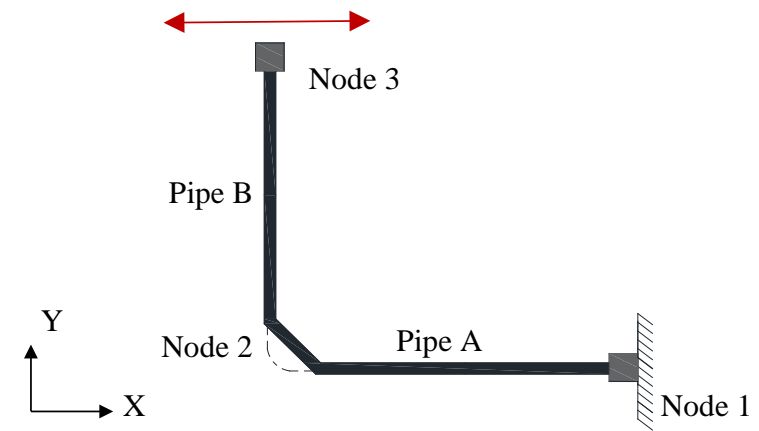

(a)

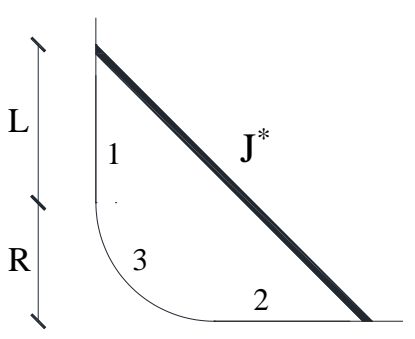

(b)

Figure 11. (a) plan view of the pipe model, and (b) detail of the elbow 
The strain demand in the critical section of the pipe was investigated by imposing a displacement at node 3 in both the positive and the negative $\mathrm{X}$ direction of the pipe model, as presented in Figure 11a. The strains in the pipes and the elbow were recorded and compared to the thresholds associated with the operational limit state (i.e. upper limit values of the strains interval defined for DLI, as defined in Table 1). The results are presented in terms of pushover curves (Figure 12), which represent the displacements of node 3 as a function of the base shear recorded at node 1 . The intervals of pipe strains corresponding to the levels defined in Table 1 are outlined with different colours. It was assumed that the displacement for the operational limit state ( $d_{O P}$ in Figure 12) corresponds to the occurrence of the upper limit pipe strains from the interval of DLI strains. It can be seen that the DLI is exceeded prior in the positive direction and the corresponding displacement is equal to $0.034 \mathrm{~m}$.

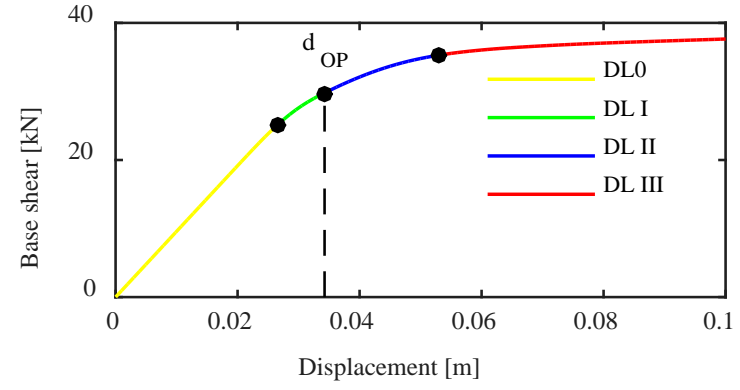

(a)

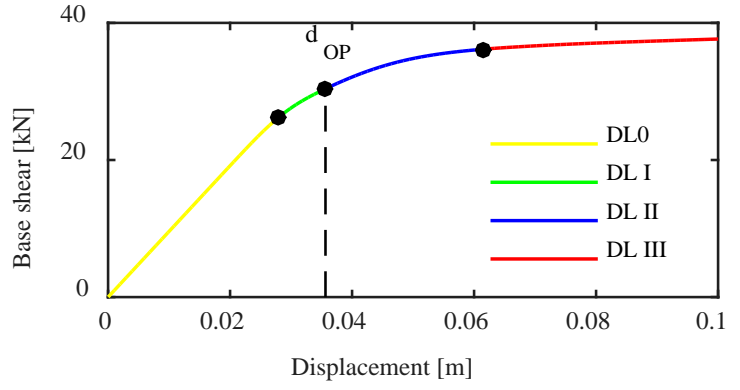

(b)

Figure 12. Pushover curves for the pipes in (a) the positive and (b) the negative direction, indicating the different damage levels in the pipes and the displacement of the operational limit state $\left(d_{O P}\right)$

The ratios between the strains at different fibres, and the limit values of the strains are shown in Figure 13, for node 1 , node 2 , and node 3 , relative to a displacement of $0.034 \mathrm{~m}$ at node 3 . Note that a ratio equal to 1 means that the $d_{O P}$ is attained. It can be observed that this condition is first attained due to the tensile strain at the elbow (node 2), which has a section that is considerably weaker than that of the other pipes in the model. The strain ratios at nodes 1 and 3 are significantly smaller than 1 , which is the limit value for the operational limit state.

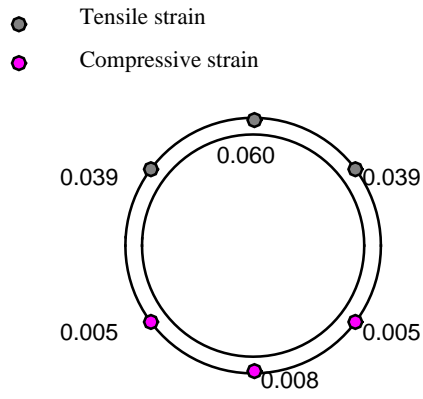

(a)

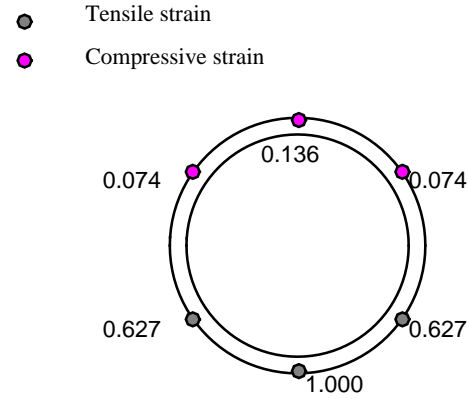

(b)

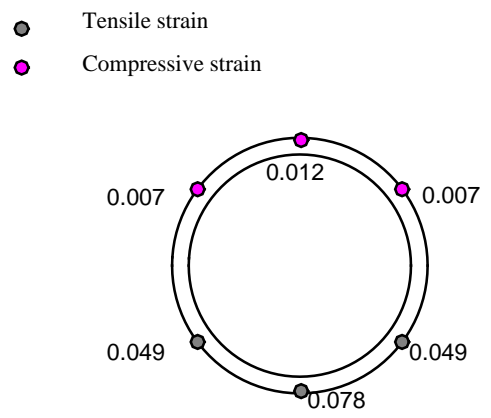

(c)

Figure 13. Ratio between strains and the DLI limit strain at different fibres of the pipe sections for (a) node 1, (b) node 2 and (c) node 3.

The displacement at which the DL I was exceeded was equal to $0.034 \mathrm{~m}$. This displacement is termed as the operational limit state displacement $d_{O P}=\alpha_{O P} h$. It should be noted that $\alpha_{O P}=0.7 \%$, since the height of the ground-level storey is $h=5.0 \mathrm{~m}$. However, it should also be noted that in the process of the evaluation of $d_{O P}$ the uncertainties were disregarded. Since the performance objective has to be evaluated with a certain confidence, the bias in the evaluation of the operational limit state displacement is acceptable. A more 
rigorous procedure for the evaluation of the limit state displacement with a designated level of confidence can also be used, according to [57][58].

Step 3: A linear model of the moment resisting frame described in Step 1 was developed. The columns were considered fixed at their bases, and all the beams were fully restrained at their ends. In the initial iteration, the frame was characterized by IPE270 beams and HE180B columns, as shown in Figure 13a. It should be noted that these sections were selected so the columns could withstand the gravity loads according to [59] requirements. The fundamental vibration period of the structure was $T_{1}=1.1 \mathrm{~s}$.

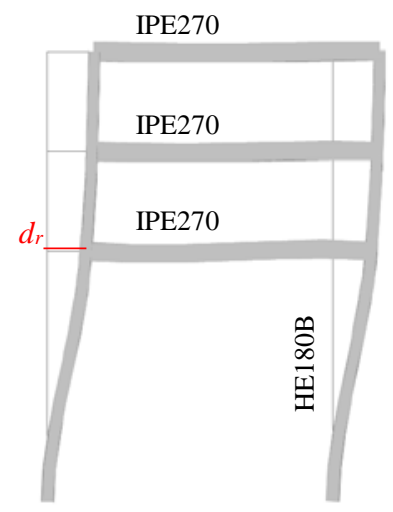

(a)

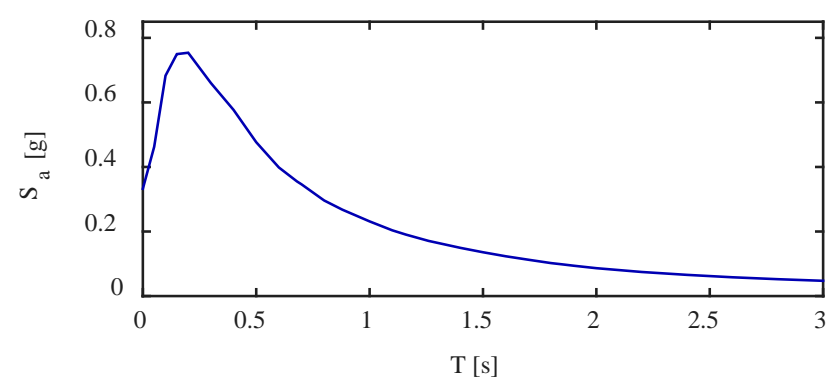

(b)

Figure 13. (a) the initial moment resisting frame; (b) the uniform hazard spectrum for the site of Ljubljana for a return period of 475 years

Seismic demand was calculated by means of a response spectrum analysis, assuming that the design seismic action was defined by the uniform hazard spectrum for the site of Ljubljana and a return period of 475 years (Figure 13b). The resulting lateral displacement of the first storey was $d_{D}=0.052 \mathrm{~m}$.

Step 4: The risk-targeted safety factor $\gamma_{O P}$ was evaluated using both numerical and closed-form solutions. The acceptable target probability was set to $P_{t, O P}=1.5 \cdot 10^{-3}$ (i.e. $7.5 \%$ in 50 years), and a standard deviation $\beta_{O P}=0.10$ was assumed, as suggested in ANNEX F of the new draft of Eurocode 8 [36] for the OP limit state. The seismic hazard function of the site of Ljubljana was taken into account, and the spectral acceleration corresponding to the fundamental period of the structure was selected as the IM.

In the case of the numerical solution, the risk-targeted spectral acceleration was evaluated by numerical integration of Eq.(3) in such a way that $\lambda_{t, O P} \approx P_{t, O P}=1.5 \cdot 10^{-3}$. The result was: $S_{a, t, O P}=0.246 \mathrm{~g}$. $S_{a, T R}$ was also directly obtained from the hazard function for the spectral acceleration at $\mathrm{T}_{1}=1.1 \mathrm{~s}$, and by considering the return period of the design seismic action ( $T_{R}=475$ years). The result was: $S_{a, T R}=0.204 \mathrm{~g}$ (Figure 14a). The risk targeted safety factor $\gamma_{O P}$ was then obtained from Eq.(10) as:

$$
\gamma_{O P}=\frac{S_{a, t, O P}}{S_{a, T R}}=\frac{0.246}{0.204}=1.21
$$




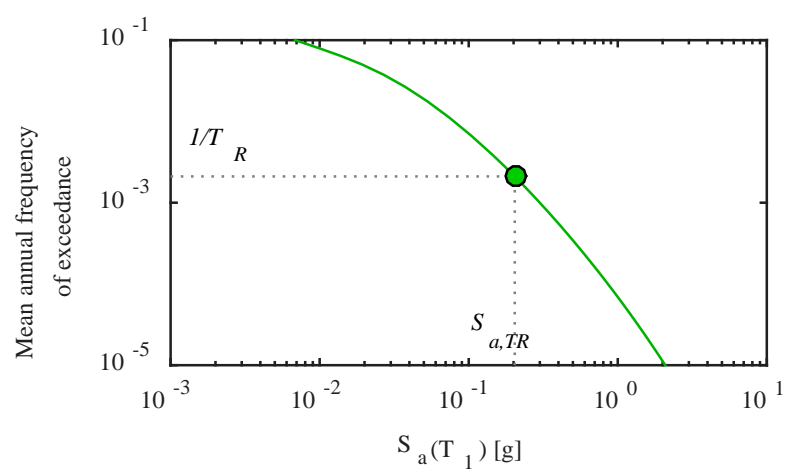

(a)

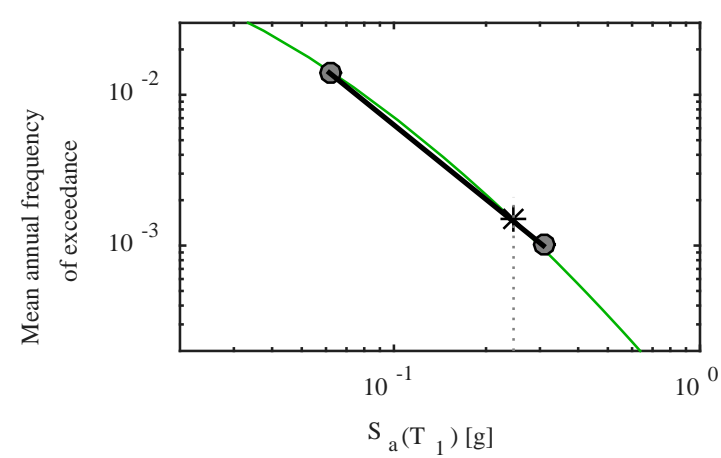

(b)

Figure 14. (a) the hazard function at the site of Ljubljana and soil type $C$ for a spectral acceleration at $T_{1}=1.1 \mathrm{~s}$ with highlighted point presenting the spectral acceleration for $T_{R}=475$ years, and (b) linear approximation of the hazard function.

The closed-form solution for the evaluation of $\gamma_{O P}$ (Eq.(12)) was considered for comparison purposes. It was found that both approaches were suitable for the evaluation of the risk-targeted safety factor. The hazard function at the location of Ljubljana was approximated in the range near $S_{a, t, O P}=0.246 \mathrm{~g}$ in order to evaluate slope $k$. It has already been shown [60][61] that the most appropriate way to estimate parameter $k$ is to approximate the hazard function to a linear function over the interval between $0.25 S_{a, t, O P}$ and $1.25 S_{a, t, O P}$ (Figure 14b). The obtained value was $k=1.7$. Assuming $\beta_{O P}=0.10$ and $P_{t, O P}=1.5 \cdot 10^{-3}$, from Eq.(12) the following expression was obtained for $\gamma_{O P}$ :

$$
\gamma_{O P}=e^{\frac{1.7 \cdot 0.1^{2}}{2}} \cdot\left(475 \cdot 1.5 \cdot 10^{-3}\right)^{-1 / 1.7}=1.23
$$

which is a similar value to that obtained on the basis of the numerical solution.

Step 5: The simplified risk-targeted decision model of Eq.(2) was applied, with $d_{D}=0.052 \mathrm{~m}, d_{O P}=\alpha_{O P} h$ $=0.035 \mathrm{~m}$, and $\gamma_{O P}=1.21$.

$d_{D} \leq \frac{\alpha_{O P} h}{\gamma_{O P}} \rightarrow 0.052 \leq 0.029$

It can be seen that the demand is greater than the capacity, which means that the structure needs to be adjusted. The dimensions of the structural element sections were increased in order to increase the stiffness of the structure, and thus reduce the demand displacement.

In the second iteration, the structure was then characterized by IPE270 beams and HE300B columns. The fundamental vibration period was reduced to $T_{1}=0.6 \mathrm{~s}$.

Steps 3 to 5 were re-evaluated. The displacement demand (Step 3) was once again evaluated using response spectrum analysis, and the value of $d_{D}=0.026 \mathrm{~m}$ was obtained. The decision model of Eq.(2) was applied (Step 5):

$d_{D} \leq \frac{\alpha_{O P} h}{\gamma_{O P}} \rightarrow 0.026 \leq 0.029$

Since the resulting displacement demand is less than the displacement capacity, it was decided that the 
structural configuration from the second iteration is acceptable.

\section{The effect of the target probability of exceeding the operational limit state on the selected structural configuration}

In the previous section, the target probability of exceedance of the operational limit state was set to $P_{t, O P}=$ $1.5 \cdot 10^{-3}$. This probability of exceedance might be too large if, for example, the expected consequence of the interruption of functionality triggered substantial economic losses for society. The stakeholders could then decide to select a lower target probability. Thus, it is interesting to investigate how the variation of $P_{t, O P}$ affects the structural configuration. Therefore, a small-scale parametric study was performed. The proposed design procedure was applied to different values of $P_{t, O P}$, which are listed in Table 2. Only the steps from 3 to 5 were re-performed for each of the selected target probabilities, because the other steps are independent of $P_{t, O P}$. The results of the design (i.e. cross-sections of the columns and beams) are summarized in Table 2. The risk-targeted safety factors $\gamma_{O P}$ for the different values of $P_{t, O P}$, which were obtained by using the numerical solution, are presented, together with the displacement capacity and demand, and the fundamental period $T_{1}$.

Table 2. Results of the design when taking different target probabilities $P_{t, O P}$ into account

\begin{tabular}{|c|c|c|c|c|c|c|}
\hline$P_{t, O P}$ & $\gamma_{O P}$ & $d_{O P} / \gamma_{O P}[\mathrm{~m}]$ & $\mathrm{d}_{\mathrm{D}}[\mathrm{m}]$ & Columns & Beams & $\mathrm{T}_{1}[\mathrm{~s}]$ \\
\hline \hline $6 \cdot 10^{-3}$ & 0.56 & 0.063 & 0.052 & HE180B & IPE270 & 1.08 \\
\hline $5 \cdot 10^{-3}$ & 0.62 & 0.056 & 0.052 & HE180B & IPE270 & 1.08 \\
\hline $4 \cdot 10^{-3}$ & 0.71 & 0.049 & 0.046 & HE200B & IPE270 & 0.90 \\
\hline $3 \cdot 10^{-3}$ & 0.80 & 0.044 & 0.041 & HE220B & IPE270 & 0.85 \\
\hline $2 \cdot 10^{-3}$ & 1.03 & 0.035 & 0.033 & HE260B & IPE270 & 0.72 \\
\hline $1 \cdot 10^{-3}$ & 1.40 & 0.025 & 0.023 & HE320B & IPE300 & 0.54 \\
\hline $5 \cdot 10^{-4}$ & 1.89 & 0.018 & 0.017 & HE400B & IPE360 & 0.41 \\
\hline $2 \cdot 10^{-4}$ & 2.70 & 0.013 & 0.012 & HE500B & IPE360 & 0.34 \\
\hline $1 \cdot 10^{-4}$ & 3.36 & 0.010 & 0.010 & HE550B & IPE400 & 0.30 \\
\hline
\end{tabular}

It is worth noting that for target probabilities higher than $4 \cdot 10^{-3}$, the structural configuration does not change anymore. This is because, in such cases, the requirements of [59] for gravity loads govern the design. For a decreasing probability $P_{t, O P}$, the operational limit state requirement becomes decisive, so that the dimensions of the structural element sections had to be increased in order to reduce the displacement demand.

The weight of one frame of the structure is presented in Figure 15 as a function of the target probability $P_{t, O P}$. The flat part of the function indicates the weight of the structural configuration required to withstand gravity loads. It can be seen that the weight, which is a measure of the cost of the structure, can increase by up to 3 times when $P_{t, O P}=1 \cdot 10^{-4}$.

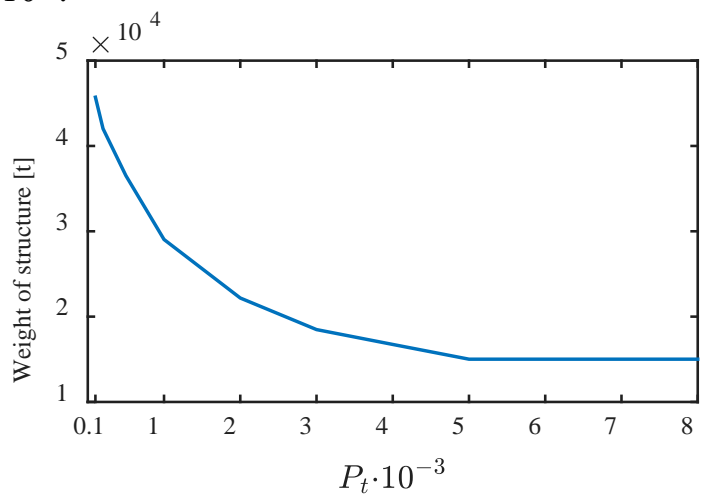

Figure 15. The weight of the structures designed according to the proposed procedure for different target probabilities $P_{t, O P}$ 
It should be noted that the $P_{t, O P}$ - weight relationship clearly depends on the decision of structural engineers about how to adjust the structure. For example, the stiffness of the frame can be increased by increasing only the dimensions of the columns, or by increasing the dimensions of the beams, or by increasing both. Increasing the section dimensions is not the only way to increase stiffness. For instance, an alternative strategy could be to change the structural typology from MRF to a braced frame. However, this solution frequently cannot be adopted, since pipe racks have to have access for maintenance underneath them.

\section{Conclusions}

The proposed risk-targeted decision model for the verification of operational limit state is based on the conventional hazard-targeted decision model introduced in Eurocode for the verification of damage limitation limit state, the IM-based risk equation [37][38] and assumed linearity between EDP of a structure and the IM. It is intentionally derived from the hazard-targeted decision model, which is familiar to engineers. As a consequence, the seismic analysis is independent of risk objective and thus identical to that defined in the code. The only difference is reflected in the capacity side of the decision model, where the capacity is defined as the ratio between the best estimate of the operational-limit-state displacement and the risk-targeted safety factor $\gamma_{O P}$ [28][43]. Therefore, the capacity can be interpreted as an indicator of allowable deformation/damage of a structure in the case of the hazard-targeted seismic design action in order to fulfil risk objective (i.e. the risk of exceedance of the operational limit state is less than the target risk). Similarly, the risk-targeted safety factor can be interpreted as a minimum multiplication factor of hazard-targeted seismic demand in order to obtain the required capacity of a structure, which has to be achieved in the design to fulfil the risk objective for the operational limit state.

Because the proposed risk-targeted decision model is based on the IM-based risk equation [37, 38] and assumed linearity between EDP of a structure and the IM, it can be alternatively derived by rearranging the IM-based decision model introduced in [37] or even EDP-based SAC/FEMA decision model $[13,15]$.

It was found that $\gamma_{O P}$ is mostly influenced by the target probability of exceeding the limit state, which should be selected on the basis of the importance of the critical equipment of an infrastructure plant. The lower is the target probability, the greater is the value of $\gamma_{O P} . \gamma_{O P}$ is also site-dependent, because it depends on the hazard function slope. It also takes into account the randomness of seismic intensity, which causes the operational limit state. If the seismic design action corresponds to a return period of 475 years, the typical values of $\gamma_{O P}$ are around 1.5, when the target probability is equal to $1 \cdot 10^{-3}$ (i.e. $5 \%$ in 50 years).

In the paper, it has been shown that the proposed risk-targeted decision model for the verification of the operational limit state can be applied in the design of pipe racks for petrochemical plants. The most challenging part of the proposed risk-targeted design procedure is to properly define the operational limitstate displacement. The procedure is developed in such a way that the operational limit-state displacement can be evaluated independently of the analysis of the structure. This offers more flexibility in the process of the design of pipes and pipe racks, which can be carried out by different design teams. This advantage of the method is lost when the dynamic interaction between primary structure and equipment cannot be neglected. In such a case, the introduced risk-targeted safety factor can still be used, but the safety verification should be applied directly to the equipment, by estimating the seismic demand on a coupled model of primary structure and equipment together and considering the risk-targeted safety factor for each equipment which is a subject of verification.

Further studies are still needed in order to overcome some limitations of the proposed decision model. Above all, more accurate modelling of the equipment will make it possible to estimate more precisely the limitstate displacement associated with the operational limit state. Moreover, if the equipment is accelerationsensitive, a model based on the limitation of the displacements may not be appropriate. However, the proposed approach could easily be adapted by introducing a decision model based on floor accelerations rather than on displacements. Another limitation of the approach arises from the fact that the expected annual 
losses are not directly taken into account, but only indirectly controlled by the selection of the target risk. Thus, additional research is needed to provide an insight into the definition of the target probability of exceedance of limit state, which should be defined rationally with consideration of direct and indirect economic losses.

Nevertheless, the proposed risk-targeted decision model could be used to extend the code further, if extensive parametric studies are carried out in order to properly define the displacement capacity for different types of critical equipment. Such parametric studies would make it possible to elaborate typical values of $\gamma_{O P}$ for different sets of input parameters (i.e. seismicity, dispersion of the limit-state intensity causing the operational limit state, and different target probabilities of exceedance of the operational limit state). Finally, further research would make it possible to use the same approach also for the verification of other relevant limit-states. This would require a proper estimation of the displacement capacity, on the basis of the level of damage allowed for the equipment at different limit states.

\section{Acknowledgements}

This research is part of the XP-RESILIENCE project, which is funded by the European Union's Horizon 2020 research and innovation programme under the Marie Sklodowska-Curie grant agreement No. 721816. The authors gratefully acknowledge the reviewers for the relevant comments, which have led to the improvement of the paper.

\section{References}

[1] CEN. Eurocode 8: Design of structures for earthquake resistance - Part 1: General rules, seismic actions and rules for buildings. EN 1998-1. Brussels: European Committee for Standardisation; 2004.

[2] NEA Committee on the Safety of Nuclear Installations. Differences in approach between nuclear and conventional seismic standards with regard to hazard definition. CSNI Integrity and Ageing Working Group; 2008.

[3] CEN. Metallic Industrial Piping - Part 3: Design and Calculation. EN 13480-3. Brussels: European Committee for Standardisation; 2002.

[4] ASME B36.19M. Stainless Steel Pipe. U.S.A.: The American Society of Mechanical Engineers; 2004.

[5] Paolacci F, Reza M shahin, Bursi OS. Seismic analysis and component design of refinery piping systems. Proceedings of the 3rd ECCOMAS Thematic Conference on Computational Methods in Structural Dynamics and Earthquake Engineering, 26-28 May 2011, Corfu, Greece: 2011.

[6] Bursi OS, Reza MS, Abbiati G, Paolacci F. Performance-based earthquake evaluation of a full-scale petrochemical piping system. J Loss Prev Process Ind 2015;33:10-22. doi:10.1016/j.jlp.2014.11.004.

[7] Celano F, Dolšek M, Žižmond J. The Evaluation Of Risk-Targeted Safety Factors And Behaviour Factor For Selected Steel Structures. Proceedings of the 16th European Conference on Earthquake Engineering, 18-21 June 2018, Thessaloniki, Greece: 2018.

[8] Sezen H, Whittaker AS. Seismic performance of industrial facilities affected by the 1999 turkey earthquake. J Perform Constr Facil 2006;20:28-36. doi:10.1061/ASCE0887-3828_200620:1_28.

[9] Krausmann E, Cruz AM, Affeltranger B. The impact of the 12 May 2008 Wenchuan earthquake on industrial facilities. J Loss Prev Process Ind 2010;23:242-8. doi:10.1016/j.jlp.2009.10.004.

[10] ICC. International Building Code. International Code Council; 2009.

[11] Ministero delle infrastrutture e dei trasporti. Norme Tecniche per le Costruzioni (NTC), 2018. DM 17 gennaio 2018, Supplemento ordinario alla Gazzetta Ufficiale n. 42 del 20 febbraio 2018 - Serie generale. Rome, Italy 2018.

[12] Caputo AC, Giannini R, Paolacci F. Quantitative seismic risk assessment of process plants. State of the art review and directions for future research. Proceedings of the ASME 2015 Pressure Vessels \& Piping Conference, July 19-23, 2015, Boston, Massachusetts, USA: 2015. doi:10.1115/PVP2015-45374.

[13] Cornell CA, Jalayer F, Hamburger RO, Foutch DA. Probabilistic basis for 2000 SAC federal emergency management agency steel moment frame guidelines. J Struct Eng 2002;128:526-33. doi:10.1061/(ASCE)0733-9445(2002)128:4(526). 
[14] Fajfar P, Dolšek M. A practice-oriented estimation of the failure probability of building structures. Earthq Eng Struct Dyn 2012;41:531-47. doi:10.1002/eqe.1143.

[15] Jalayer F. Direct probabilistic seismic analysis: implementing non-linear dynamic assessments. Stanford University, Stanford, CA, 2003.

[16] DOE. Natural phenomena hazards design and evaluation criteria for Department of Energy Facilities. DOESTD-1020-94, U. S. Dept. of Energy, Washington, D. C., 1994.

[17] Kennedy R, Short SA. Basis for seismic provisions of DOE-STD-1020. Report UCRL-CR-111478, S/C B235302, Brookhaven Natl.Lab.BNL-52418. Livermore (CA): Lawrence Livermore National Lab. 1994.

[18] Banon H, Cornell CA, Crouse CB, Marshall PW, Nadim F, Younan AH. ISO seismic design guidelines for offshore platforms. Proceedings of the 20th OMAE, Offshore Mechanics and Arctic Engineering Conference, Rio de Janiero, June: 2011.

[19] Zareian F, Krawinkler H. Assessment of probability of collapse and design for collapse safety. Earthq Eng Struct Dyn 2007;36:1901-14. doi:10.1002/eqe.702.

[20] Lazar Sinković N, Brozovič M, Dolšek M. Risk-based seismic design for collapse safety. Earthq Eng Struct Dyn 2016;45:1451-71. doi:10.1002/eqe.2717.

[21] Dolšek M, Brozovič M. Seismic response analysis using characteristic ground motion records for risk-based decision-making (3R method). Earthq Eng Struct Dyn 2016;45:401-20. doi:10.1002/eqe.2664.

[22] Krawinkler H, Zareian F, Medina RA, Ibarra LF. Decision support for conceptual performance-based design. Earthq Eng Struct Dyn 2006;35:115-33. doi:10.1002/eqe.536.

[23] Mackie KR, Stojadinovic B. Performance-based seismic bridge design for damage and loss limit states. Earthq Eng Struct Dyn 2007;36:1953-71. doi:10.1002/eqe.699.

[24] Franchin P, Pinto PE. Method for probabilistic displacement-based design of RC structures. J Struct Eng 2011;138:585-91. doi:10.1061/(ASCE)ST.1943-541X.0000492.

[25] Vamvatsikos D, Aschheim MA. Performance-based seismic design via yield frequency spectra. Earthq Eng Struct Dyn 2016;45:1759-78. doi:10.1002/eqe.2727.

[26] Franchin P, Petrini F, Mollaioli F. Improved risk-targeted performance-based seismic design of reinforced concrete frame structures. Earthq Eng Struct Dyn 2018;47:49-67. doi:10.1002/eqe.2936.

[27] ASCE. Minimum design loads for buildings and other structures. ASCE/SEI Standard 7-10. American Society of Civil Engineers ASCE; 2010.

[28] Žižmond J, Dolšek M. Formulation of risk-targeted seismic action for the force-based seismic design of structures. Earthq Eng Struct Dyn 2019. doi:10.1002/eqe.3206.

[29] Luco N, Ellingwood BR, Hamburger, Ronald O Hooper JD, Kimball JK, Kircher CA. Risk-targeted versus current seismic design maps for the conterminous United States. Proceedings of Structural Engineers Association of California 76th Annual Convention, Lake Tahoe, California: 2007.

[30] Douglas J, Ulrich T, Negulescu C. Risk-targeted seismic design maps for mainland France. Nat Hazards 2013;65:1999-2013. doi:10.1007/s11069-012-0460-6.

[31] Silva V, Crowley H, Bazzurro P. Exploring risk-targeted hazard maps for Europe. Earthq Spectra 2016;32:1165-86. doi:10.1193/112514EQS198M.

[32] Jalayer F, Cornell CA. A Technical Framework for Probability-Based Demand and Capacity Factor Design (DCFD) Seismic Formats. PEER Rep 2003/08 2003.

[33] Bradley BA, Dhakal RP. Error estimation of closed-form solution for annual rate of structural collapse. Earthq Eng Struct Dyn 2008;37:1721-37. doi:10.1002/eqe.

[34] Lazar N, Dolšek M. Incorporating intensity bounds for assessing the seismic safety of structures: Does it matter? Earthq Eng Struct Dyn 2014;43:717-38. doi:10.1002/eqe.2368.

[35] Kosič M, Dolšek M, Fajfar P. Dispersions for the pushover-based risk assessment of reinforced concrete frames and cantilever walls. Earthq Eng Struct Dyn 2016;45:2163-83. doi:10.1002/eqe.2753.

[36] CEN TC250 SC8. Eurocode 8: Design of structures for earthquake resistance - Part 1: General rules, seismic action and rules for buildings. Working draft. Brussels: European Committee for Standardisation; 2018.

[37] Cornell CA. Calculating building seismic performance reliability: A basis for multi-level design norms. Proceeding of 11th World Conference on Earthquake Engineering, 23-28 June 1996, Acapulco, Mexico: 1996.

[38] McGuire RK. Seismic hazard and risk analysis. Earthquake Engineering Research Institute, EERI Publication no MNO-10. 2004.

[39] Vamvatsikos D. Derivation of new SAC/FEMA performance evaluation solutions with second-order hazard approximation. Earthq Eng Struct Dyn 2013;42:1171-88. doi:10.1002/eqe.2265.

[40] Vamvatsikos D, Cornell CA. Incremental dynamic analysis. Earthq Eng Struct Dyn 2002;31:491-514. doi:10.1002/eqe.141. 
[41] Fajfar P. A nonlinear analysis method for performance based seismic design. Earthq Spectra 2000;16:573-92.

[42] Veletsos AS, Newmark NM. Effect of inelastic behaviour on the response of simple systems to earthquake motions. Proceedings of the 2nd World Conference on Earthquake Engineering, Japan: 1960.

[43] Dolšek M, Lazar Sinković N, Žižmond J. IM-based and EDP-based decision models for the verification of the seismic collapse safety of buildings. Earthq Eng Struct Dyn 2017;46:2665-82. doi:10.1002/eqe.2923.

[44] Žižmond J, Dolšek M. The formulation of risk-targeted behaviour factor and its application to reinforced concrete buildings. 16th World Conf Earthq 2017:1-11.

[45] Fajfar P. Analysis in seismic provisions for buildings: Past, present and future. Bull Earthq Eng 2018;16:2567608. doi:10.1007/978-3-319-75741-4_1.

[46] Žižmond J. Force-based seismic design of reinforced concrete buildings for target reliability. Doctoral dissertation. University of Ljubljana, Faculty of Civil and Geodetic Engineering, 2016.

[47] Woessner J, Laurentiu D, Giardini D, Crowley H, Cotton F, Grünthal G, et al. The 2013 European Seismic Hazard Model: key components and results. Bull Earthq Eng 2015;13:3553-96. doi:10.1007/s10518-0159795-1.

[48] RINTC Workgroup. Results of the 2015-2017 Implicit seismic risk of code conforming structures in Italy (RINTC) project. ReLUIS report, Rete dei Laboratori Universitari di Ingegneria Sismica (ReLUIS), Naples, Italy, available at http://www.reluis.it/. 2018.

[49] Drake RM, Walter RJ. Design of Structural Steel Pipe Racks. AISC Eng J 2010;47:241-52.

[50] Vathi M, Karamanos SA, Kapogiannis IA, Spiliopoulos K V. Performance Criteria for Liquid Storage Tanks and Piping Systems Subjected To Seismic Loading. J Press Vessel Technol 2017:1-12. doi:10.1115/1.4036916.

[51] Bursi OS, di Filippo R, La Salandra V, Pedot M, Reza MS. Probabilistic seismic analysis of an LNG subplant. J Loss Prev Process Ind 2018;53:45-60. doi:https://doi.org/10.1016/j.jlp.2017.10.009.

[52] Azizpour O, Hosseisni M. A verification of ASCE Recommended Guidelines for seismic evaluation and design of combination structures in petrochemical facilities. J Appl Sci 2009;21. doi:10.3923/jas.2009.3609.3628.

[53] Caprinozzi S, M. Ahmed M, Paolacci F, Bursi OS, La Salandra V. Univariate fragility models for seismic vulnerability assessment of refinery piping systems. Proceedings of the ASME 2017 Pressure Vessels and Piping Conference, July 16-20, 2017, Waikoloa, Hawaii, United States: 2017. doi:10.1115/PVP2017-65138.

[54] Bursi OS. Report on Mechanical Characterization of Selected Steel for Cyclic Loading and Temperature sensitivity. Deliverable 4.1, INDUSE-2-SAFETY, Grant No. RFSR-CT-2014-2010002. 2016.

[55] CSA. Oil and gas pipeline systems. Exdale, Ontario, Canada: Canadian standards association; 2007.

[56] McKenna F. OpenSees: a framework for earthquake engineering simulation. Comput Sci Eng 2011;13:58-66. doi:10.1109/MCSE.2011.66.

[57] Franchin P, Pagnoni T. A general model of resistance partial factors for seismic assessment and retrofit. Proceedings of the 16th European Conference on Earthquake Engineering, 18-21 June 2018, Thessaloniki, Greece: 2018.

[58] Franchin P, Pinto PE, Rajeev P. Confidence factor? J Earthq Eng 2010;14:989-1007. doi:10.1080/13632460903527948.

[59] CEN. Eurocode 3: Design of steel structures - Part 1-1: General rules and rules for buildings. EN 1993-1-1. Brussels: European Committee for Standardisation; 2005.

[60] Dolšek M, Fajfar P. The effect of masonry infills on the seismic response of a four-storey reinforced concrete frame—a deterministic assessment. Eng Struct 2008;30:1991-2001. doi:10.1016/j.engstruct.2008.01.001.

[61] Dolšek M. Simplified method for seismic risk assessment of buildings with consideration of aleatory and epistemic uncertainty. Struct Infrastruct Eng 2012;8:939-53. 